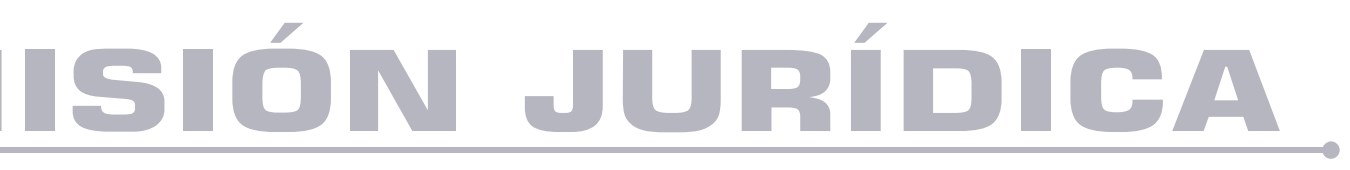

\title{
La revolución y el estatuto constitucional siciliano del año 1848
}

The revolution and sicilian constitutional statute of 1848

Autor: Angelo Grimaldi

DOI: https://doi.org/10.25058/1794600X.1042

\footnotetext{
SP MISIÓN JURÍDICA A 


\title{
LA RIVOLUZIONE E LO STATUTO COSTITUZIONALE SICILIANO DEL 1848*
}

\author{
La revolución y el estatuto constitucional siciliano del año \\ 1848
}

The revolution and sicilian constitutional statute of 1848

\section{A revolução e o estatuto constitucional da sicília do ano 1848}

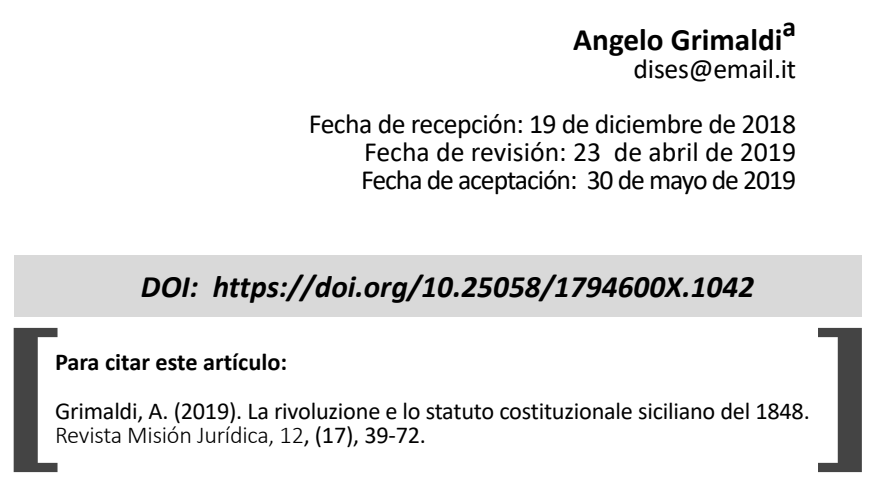

\section{SOMMARIO}

La Sicilia apre la stagione delle rivoluzioni del 1848 con i moti di Palermo del 12 gennaio. Si chiede l'autonomia, non si tratta di un'istanza separatistica ma di una seria opposizione al centralismo napoletano. Il parlamento fu eletto a suffragio ristretto e non ampio, quindi non si può parlare di "parlamento costituente" come espressione della sovranità popolare. Tuttavia, il parlamento del 1848 deriva da un evento rivoluzionario, da una rottura costituzionale che determinò l'inizio di un nuovo regime politico-costituzionale, cioè una nuova forma di governo, ed in questo senso si può considerare espressione di potere costituente. Il sistema temporaneamente si resse su un solo attore costituzionale, il parlamento quale luogo di rappresentanza prevalentemente di nobili e borghesi. Dalla Costituzione siciliana emerge una forma istituzionale eclettica o mescidata tra l'impianto costituzionale americano, la Costituzione francese del 1848 e il sistema inglese precedente alle due grandi rivoluzioni. Lo schema siciliano implica una separazione dei poteri che rende possibile l'influenza ex post di un organo sulla funzione dell'altro, uno dei due organi costituzionali è però claudicante: il re, pur partecipando (indirettamente) per mezzo dei ministri alla funzione legislativa, non è uno dei tre organi legislativi, non interviene personalmente nel processo legislativo, la Costituzione priva il re di

\footnotetext{
* Artículo de investigación científica y tecnológica. This paper is the result of the academic activity of the author in the Centre for Legal, political, and Constitutional Research.

a. Professore di Ricerca di Diritto e Storia Costituzionale DISES-Centro di Ricerche Giuridiche e Politico-Costituzionali Sede di Forlì - MIUR-Anagrafe Nazionale delle Ricerche n. 58188 GZN.
} 
intervenire con l'atto di sanzione, ma attribuisce ad esso lo strumento del veto sospensivo "limitato". La Costituzione siciliana del 1848 racchiude una concezione "quasi dualistica" (dualismo zoppo), due corpi costituzionali posti "quasi" in posizione paritaria: il parlamento e il re.

\section{PAROLE CHIAVE}

Autonomia, costituzione eclettica, forma quasi dualistica, dualismo zoppo, sistema monistico, supremazia del parlamento, sovranità della Costituzione.

\section{RESUMEN}

Sicilia abre la estación de las revoluciones del año 1848 con los motínes de Palermo del día 12 de Enero. Lo que se pide es la autonomía, no se trata de separatismo, sino de una seria oposición al centralismo napolitano. El Parlamento no fue elegido por sufragio amplio, sino limitado, por lo cual no se puede hablar de un «parlamento constituyente», expresión de la soberanía popular. Sin embargo, el Parlamento del año 1848 deriva de un acontecimiento revolucionario, una fractura constitucional que determinó el inicio de un nuevo régimen político/constitucional, es decir una nueva forma de gobierno, y en este sentido puede considerarse expresión de un poder constituyente. El sistema se fundamentaba temporalmente en un único actor constitucional, el Parlamento como una representación predominantemente noble y burgués. De la Constitución de Sicilia emerge una forma institucional ecléctica o mezclada entre el sistema constitucional estadounidense, aquello inglés - tal como era anteriormente a las dos grandes revoluciones - y la Constitución francesa del año 1848. El régimen siciliano implíca una separación de poderes que hace posible una influencia ex post por parte de un órgano sobre otro: uno de los dos es "claudicante": aunque el Rey participe (indirectamente) en la función legislativa por medio de los ministros, él no es uno de los tres órganos legislativos, ni interviene personalmente en el proceso legislativo. La Constitución no permite al Rey intervenir con el acto de sanción, sino le confiere el instrumento de veto suspensivo «limitado». La Constitución siciliana del año 1848 entraña un concepto «cuasi dualista» (dualismo desbalanceado), dos órganos constitucionales puestos en una posición de "cuasi" igualdad: El Parlamento y el Rey.

\section{PALABRAS CLAVE}

Autonomia, constitución ecléctica, forma casi dualista, sistema monista, dualismo desbalanceado, supremacía del parlamento, soberanía de la constitución.

\section{RESUMO}

A Sicília abre a temporada das revoluções de 1848 com os movimentos de Palermo de 12 de janeiro. É necessária autonomia, não se trata de separatismo, mas de séria oposição ao centralismo napolitano. 0 parlamento foi eleito por sufrágio restrito e não amplo, por isso não podemos falar de um "parlamento constituinte" como uma expressão de soberania popular. No entanto, o parlamento de 1848 deriva de um evento revolucionário, de uma ruptura constitucional que determinou o início de um novo regime político-constitucional, ou seja, uma nova forma de governo, e, nesse sentido, pode ser considerada uma expressão do poder constituinte. 0 sistema manteve temporariamente um único ator constitucional, o parlamento como local de representação principalmente de nobres e burgueses. Da Constituição da Sicília emerge uma forma institucional eclética ou mista entre a estrutura constitucional americana, a Constituição francesa de 1848 e o sistema inglês anterior às duas grandes revoluções. 0 esquema siciliano implica uma separação de poderes que possibilita a influência ex post de um órgão sobre a função do outro, no entanto, um dos dois órgãos constitucionais está mancando: o rei, enquanto participa (indiretamente) dos ministros na função legislativa, não é um dos três órgãos legislativos, não intervém pessoalmente no processo legislativo, a Constituição priva o rei de intervir com a sanção, mas atribui a ele o instrumento do veto suspensivo "limitado". A Constituição siciliana de 1848 contém uma concepção "quase dualista" (dualismo coxo), dois órgãos constitucionais colocados "quase" em uma posição igual: o parlamento e o rei.

\section{PALAVRAS CHAVE}

Autonomia, constituição eclética, forma quase dualística, sistema monístico, dualismo desequilibrado, supremacia do parlamento, soberania da constituição. 


\section{ABSTRACT}

Sicily opens the season of the 1848 revolutions with the movements of Palermo of January 12th. Autonomy is sought. It is not about separatism but rather a serious opposition to Neapolitan centralism. The Parliament was elected by limited, not broadsuffrage, therefore it is not possible to talk about a 'constituent Parliament', an expression of popular sovereignty.

However, the Parliament of 1848 originates from a revolutionary event, a constitutional breach which triggered the beginning of a new political/ constitutional regime, a new form of government, which can be considered as the expression of a constituent power. The system temporarily leant on a single constitutional actor, the Parliament as the place where predominantly nobles and bourgeoises were represented. The Sicilian Constitution foresees an eclectic institutional setting, which combines traits of the American constitutional system, the French Constitution of 1848 and the English system -as it was prior to the two great revolutions. This configuration entails a separation of powers which makes possible an ex post influence of one body on the functioning of the other. One of the two constitutional bodies is, nonetheless, limping: even though the King could (indirectly) participate in the legislative function through his ministries, it was not one of the three legislative bodies. The Constitution deprives the King of its faculty of intervention with the royal assent but grants him the power of "limited" suspensive veto. The Sicilian Constitution of 1848 enshrines a 'quasi-dualistic' concept ("limping dualism"), two constitutional bodies placed 'almost' on an equal footing: The Parliament and the King.

\section{KEYWORDS}

Autonomy, eclectic constitution, quasidualistic system, one-tier system (o "monistic system"), limping dualism, supremacy of the Parliament, sovereignty of the Constitution.

\section{INTRODUZIONE}

La Sicilia apre la stagione delle rivoluzioni del 1848 con i moti di Palermo del 12 gennaio ${ }^{1}$. La "rivoluzione" fu annunciata qualche giorno prima:

1. VILLARI, Rosario, Storia dell'Europa contemporanea, vol. I, Bari, Laterza, 1975, p. 225. un proclama, il cui autore era Francesco Bagnasco, fissava il 12 gennaio 1848 (coincideva con il $38^{\circ}$ compleanno del re Ferdinando II) come giorno nel quale il "popolo" sarebbe stato chiamato ad insorgere.

Siciliani! Il tempo delle preghiere inutilmente passò, inutili le proteste, le suppliche, le pacifiche dimostrazioni.... Ferdinando tutto ha sprezzato, e noi Popolo nato libero, ridotto nelle catene e nella miseria, tarderemo ancora a riconquistare i nostri legittimi diritti? All'armi, figli della Sicilia: la forza di tutti è onnipossente... Il giorno 12 gennaio 1848, all'alba, segnerà l'epoca gloriosa della nostra universale rigenerazione. Palermo accoglierà con trasporto quanti siciliani armati si presenteranno al sostegno della causa comune, a stabilire riforme, istituzioni analoghe al progresso del secolo, volute dall'Europa, dall'Italia e da Pio. - Unione, ordine, subordinazione ai capi - rispetto a tutte le proprietà. Il furto vien dichiarato delitto di alto tradimento alla causa patria, e come tale punito. Chi sarà mancante di mezzi ne sarà provveduto. Con giusti principi, il Cielo seconderà la giustissima impresa - Siciliani all'armi².

La "rivoluzione" di Palermo del 12 gennaio 1848 appare sin dalle prime, priva di organizzazione, sembra una rivoluzione "spontanea", alimentata dalla forza della suggestione, senza barricate, con poche armi. La gente si affolla per le vie del centro di Palermo curiosa di assistere all'inevitabile evento rivoluzionario. Leggiamo alcuni passi suggestivi di Cesare Spellanzon:

... le vie si andavano popolando, e tutti guardavano se i congiurati si mostrassero, se da qualche parte fosse dato il segnale della rivoluzione [...] I patrioti più ansiosi di azione si stupiscono, vedendo che l'atteso segnale tarda ad essere dato [...] Pasquale Miloro, spinto dalla moglie Santa Diliberto [...] esce armato nella via: Pasquale Buscemi leva fuori uno schioppo, che teneva nascosto: altri ancora accorrono armati, Pietro Amodeo, l'avvocato Antonio Jacona, Pasquale Bruno, Francesco Ciaccio, Giacinto Carini, Damiano Lo Cascio. In piazza della Fieravecchia s'aduna gente in maggior numero, ad ascoltare la parola incitatrice del giovane avvocato Paolo Paternostro: ed è qui che accorre Giuseppe La Masa, sdegnato perché i membri del Comitato direttore non si fanno vedere, e perché mancano le armi, tanto

2. Il testo si trova in, Ruggero Settimo e la Sicilia, Documenti sulla Insurrezione Siciliana del 1848, Palermo, marzo 1848, p. 1. 
che, da qualche parte, s'incomincia a parlare di tradimento. Quanti erano in questa piazza, vedendo arrivare il biondo La Masa, armato di schioppo, deciso all'azione, immaginano che egli sia il rappresentante dell'invisibile Comitato, e l'ascoltano fiduciosi come se fosse il capo della sommossa [...] Le improvvisate squadre della rivoluzione avanzano per le vie in un suggestivo disordine, forse senza una meta, quasi senza uno scopo ${ }^{3}$.

Fino al 13 gennaio solo i poveri della città sostennero i tumulti, a loro si unirono alcune centinaia di contadini accorsi dai paesi vicini: "Nella notte cominciarono a giungere ajuti a' sollevati dalle campagne e dai comuni vicini; primi furono sessanta contadini di Villabate; di poi altri di Misilmeri e di altri luoghi"'. Alla fine del primo giorno Giuseppe La Masa cercò di dare alla "rivoluzione" un governo provvisorio. In una casa della Fieravecchia si formò un Comitato provvisorio presieduto da La Masa e composto da Giuseppe Oddo, il barone Andrea Bivona, Santoro, Antonio Jacona, Porcelli, Corteggiani, Lo Cascio, Enea, Palizzolo, Amodei, Pasquale Meloro, Pasquale Bruno, i tre fratelli Ciancioli, Rosario Bagnasco, Leonardo Decarlo, fratelli Carini, Villafiorita, i due fratelli D’Ondes, Enrico Fardella, Antonino Faia, Rosolino Capace ${ }^{5}$.

Il Comitato provvisorio invitava il Municipio di Palermo a riunirsi per costituire un Comitato definitivo, che poi si riunì il 14 gennaio $\mathrm{e}$ diede vita a quattro comitati (il Comitato provvisorio, che si era costituito il 12 gennaio, si fuse nei quattro Comitati): uno all'Annona presieduto da Giuseppe Paternò marchese di Spedalotto (nato a Palermo il 27 aprile 1794, secondogenito del marchese di Spedalotto, aveva raggiunto il grado di colonnello dell'Esercito delle Due Sicilie, si dimise per prendere parte ai moti del 1848); uno alla Difesa e Sicurezza Pubblica presieduto da Emanuele Requesenz Bonanno principe di Pantelleria (successe al fratello Michele che non aveva avuto figli. Con Reale Rescritto del 14 maggio 1847 venne

3. SPELLANZON, Cesare, Storia del Risorgimento e dell'Unità d'Italia, Vol. III, Milano, Rizzoli \& C., 1936, pp. 471-474.

4. TUROTTI, Felice, Storia d'Italia continuata da quella di Carlo Botta, dal 1814 al 1854, volume terzo, Milano, Pagnoni Tipografo Editore, 1855 , p. 57.

5. Collezione Officiale degli Atti del Comitato Generale di Sicilia nell'anno 1848, Palermo, nella Stamperia e Libreria di Antonio Muratori Tipografo del Ministero della Giustizia, 1848, pp. 3-4. riconosciuto nel titolo di Principe di Pantelleria); uno per le Finanze presieduto da Francesco Paolo Starabba marchese di Rudinì (padre di Antonio che fu più volte ministro e presidente del Consiglio dei ministri a fine Ottocento); uno per le Informazioni presieduto da Ruggero Settimo ${ }^{6}$ (nato a Palermo nel 1778, ammiraglio della Marina borbonica, appartenente alla famiglia dei principi di Fitalia e dei marchesi di Giarratana).

Il 21 gennaio il luogotenente del re comunicava a Giuseppe Paternò, marchese di Spedalotto, che il 18 gennaio il re aveva emanato quattro decreti con cui si ridefiniva l'ordinamento della Sicilia. Più in particolare veniva stabilito che tutti gli uffici civili (ed ecclesiastici) sarebbero stati attribuiti esclusivamente ai siciliani ${ }^{7}$, si istituiva la Luogotenenza in Sicilia, affidata ad un principe reale o a un distinto personaggio, con l'ausilio di due direttori. Quest'ultimi potevano essere scelti tra i sudditi di qualsiasi parte del Regno, le cause dei siciliani venivano giudicate fino all'ultimo appello in Sicilia, sarebbe stato istituito in Sicilia un supremo tribunale di giustizia, indipendente dal supremo tribunale di giustizia di Napoli, veniva confermata l'abolizione della feudalità, veniva emanata una nuova legge sulla stampa e un'amnistia per tutti i delitti politici commessi in occasione degli ultimi avvenimenti siciliani, purché tutti i responsabili rientrassero nell'ordine entro due giorni. Inoltre, si ampliavano le attribuzioni alle Consulte di Napoli e di Sicilia.

Giuseppe Paternò così rispose:

Il Comitato, dunque, fedele interprete del fermo proponimento del popolo, non può che insistere nelle idee già partecipate per mio mezzo all'E.V. che le armi non saranno deposte, né le ostilità sospese, se non quando la Sicilia, se riunita in Palermo in general Parlamento, adatterà ai tempi la costituzione che da molti anni ha posseduta, che, sotto l'influenza della Gran Bretagna, fu riformata nel 1812, e che col decreto regio dell'11 novembre 1816 fu implicitamente confermata ${ }^{8}$.

6. Ruggero Settimo e la Sicilia, op. cit, pp. 1-3; SAN MARTINO DE SPUCCHES, Francesco, La storia dei feudi e dei titoli nobiliari di Sicilia, Palermo, Scuola Tipografica “Boccone del Povero", 1927, p. 396.

7. Legislazione Positiva del Regno delle Due Sicilie, dal 1806 fino a tutto il 1848 (a cura di Francesco Dias), Napoli, presso Borel e Bompard, 1846, p. 1798.

8. SIMONCINI SCAGLIONE, Giovanni, Dal 48 al 60, Ricordi storici, Palermo, Carmelo Maniscalco Editore, 1890, p. 33. 


\section{METODOLOGIA}

Questo lavoro di ricerca rappresenta l'ultima tappa dell'esperienza costituzionale siciliana ottocentesca. I moti rivoluzionari scoppiano il 12 gennaio 1848, si parla di rigenerazione, di rinnovamento, vengono coinvolti nel conflitto contro i borboni poveri, contadini, braccianti, artigiani, donne. Le prime due esperienze (1812, 1820) possono essere inquadrate nella generale tendenza a realizzare una forma di decentramento istituzionale e di riconoscimento di autonomia amministrativa. Le richieste dei siciliani rimasero nell'alveo delle istanze "autonomistiche" e non "separatistiche". La rivoluzione quarantottesca e la conseguente Costituzione è riconducibile in modo piano alle due precedenti esperienze? Quale forma di governo è individuabile dal testo costituzionale? Attraverso un esame comparato degli istituti giuridici e dei fatti costituzionali con quelli francesi, nord americani e con l'esperienza costituzionale inglese, è stato possibile inquadrare il fermento politico-costituzionale siciliano anche del 1848 nell'ambito del più vasto processo costituzionale europeo. L'esperienza siciliana è parte di un processo più ampio, internazionale e liberale i cui contenuti ideali e le cui azioni sono riconducibili alle esperienze costituzionali europee e nord americane. Tuttavia, rispetto ai primi due sconvolgimenti, non si può non riconoscere alla Costituzione siciliana del '48, una sua specificità a tal punto che la forma di governo che ne esce fuori è definibile "quasi dualistica" (dualismo ineguale). Essa presenta caratteristiche in parte diverse rispetto anche allo schema introdotto dalla Costituzione francese del 1848. La sistemazione metodologica è stata pervasa dalla necessità di seguire un ordine simmetrico, le classificazioni, l'esame esegetico, l'analisi dei fatti rivoluzionari e degli istituti giuridici ha avuto come obiettivo quello di far emergere la forma di governo in qualche modo riconducibile (nonostante la specificità) ai principi del costituzionalismo europeo e nord americano. La "rigenerazione", capeggiata da nobili e borghesi (quale compromesso tra le istanze socialisteggianti e le posizioni conservatrici), ma appoggiata nella fase cruenta anche dal popolo, genera una Costituzione moderata, liberale, di "compromesso", che introduce una forma di governo "quasi dualistica" (dualismo zoppo o dualismo ineguale), comunque riferibile al quadro costituzionale europeo e nord americano.

\section{QUADRO STORICO DI RIFERIMENTO: COSTITUZIONE FRANCESE DEL 1830 E COSTITUZIONE BELGA DEL 1831. LA COSTITUZIONE DEL REGNO DELLE DUE SICILIE DEL 10 FEBBRAIO 1848}

\subsection{Costituzione francese del 1830}

Prima di commentare brevemente la Costituzione ferdinandea (anche per meglio comprendere gli eventi politico-costituzionali successivi), credo sia necessaria una breve lettura dei fatti, che poi sfociarono nelle tre giornate di luglio 1830 (27, 28 e 29 luglio, le "trois glorieuses"), della Costituzione del 9 agosto 1830, della rivoluzione e Costituzione belga del 1831.

La rivoluzione di luglio 1830 scoppia a causa delle quattro ordinanze, emanate dal ministro Polignac ai sensi dell'articolo 14 della Carta del 1814, che sospendevano la libertà di stampa, scioglievano la camera dei Deputati, modificavano il sistema elettorale e convocavano i collegi elettorali per il 13 settembre 1830.

Nelle elezioni del 1827 i liberali ottennero il maggior numero di seggi alla camera dei Deputati. Nel novembre 1829 Carlo X (il fratello Luigi XVIII era deceduto il 16 settembre 1824) nominò come primo ministro il principe di Polignac (ultra-royalistes, appartenente ai monarchici conservatori che propugnavano il ripristino della monarchia assoluta). In quegli anni si scontravano due opposte interpretazioni della Carta del 4 giugno 1814: per Carlo $\mathrm{X}$, secondo una lettura puramente formale della Carta, la Corona aveva l'esclusivo diritto di scegliere liberamente i propri ministri, dall'altro i liberali, sostenevano che la scelta dei ministri da parte del sovrano, doveva ricadere su persone di fiducia delle camere, in modo da raccogliere attorno al Gabinetto l'appoggio del parlamento, richiamando per questa via una consuetudine instaurata dal fratello Luigi XVIII, anche se non imposta dalla Carta del 1814.

Il regime parlamentare non era formalmente organizzato dalla Carta, ma fu introdotto dalla prassi costituzionale sotto l'influenza di Luigi XVIII il quale era vissuto in Inghilterra e cercò di applicare il sistema parlamentare inglese, scegliendo ministri che avessero la fiducia delle camere (le camere, in assenza di un potere di interpellanza, non potevano manifestare il loro 
parere sulla politica del gabinetto, ma a partire dal 1817 la discussione del bilancio consentì di controllare tutta l'attività politica del governo). Carlo X cercò di fermare la deriva del sistema francese verso il parlamentarismo; la scelta del primo ministro Polignac (personaggio ostile ai liberali) non rappresentava una violazione formale del testo della Carta del 1814, tuttavia indicava in modo chiaro un orientamento diverso da quello inaugurato da Luigi XVIII.

Il 16 marzo 1830, in occasione dell'apertura della sessione parlamentare, la maggioranza liberale della camera dei deputati, espresse la sfiducia al ministero guidato dal principe di Polignac attraverso il noto "appello dei 221". Carlo X il giorno dopo emanò un'ordinanza con cui aggiornava la sessione dei lavori parlamentari al 1 settembre 1830, mentre il 16 maggio 1830 sciolse la camera dei deputati nella speranza di ricostruire una maggioranza a lui favorevole. Alle elezioni del 23 giugno e del 19 luglio 1830 i liberali ottennero 274 seggi (53 seggi in più rispetto alle precedenti elezioni). Alla fine Carlo $\mathrm{X}$ e il primo ministro Polignac con le ordinanze del 25 luglio 1830 scatenarono la rabbia delle classi popolari (si trattò di una vera e propria forzatura del contenuto dell'art. 14 della Carta più che una interpretazione estensiva. L'ultimo passaggio dell'art. $14,{ }^{9}$ introducendo una riserva molto estesa, cioè senza il successivo e ordinario passaggio parlamentare, limitava il ricorso alle ordinanze soltanto ai casi in cui fosse in discussione la sicurezza dello Stato. Nel processo ai ministri di Carlo $\mathrm{X}$ alla frase in questione fu attribuita il significato "quando lo Stato sia in pericolo" e non quello "nell'interesse dello Stato").

Le tre giornate insurrezionali di Parigi (costrinsero il re alla fuga) videro le classi popolari in prima linea sulle barricate che sorsero lungo le vie della città, tuttavia la direzione del movimento rimase controllato dai liberali, diffidenti tanto dei repubblicani che di Carlo X. La borghesia liberale fece leva sulla paura suscitata dalla rivolta popolare per ridimensionare le rivendicazioni dei repubblicani e proporre sul trono il cugino

9. Articolo 14: "Il Re è il Capo supremo dello Stato, comanda le forze di terra e di mare, dichiara la guerra, fa i trattati di pace, d'alleanza e di commercio, provvede alle nomine per tutti gli impieghi dell'amministrazione, e fa i regolamenti e le ordinanze necessarie per l'esecuzione delle leggi e la sicurezza dello Stato", in SAITTA, Armando, Costituenti e costituzioni della Francia moderna, Torino, 1952, p. 247 del re, Luigi Filippo d'Orléans, il quale si impegnò a rispettare la Costituzione e riprendere la tradizione parlamentare iniziata dal cugino Luigi XVIII. Scrive Louis De Bonald:

La révolution de juillet eut dû n'être qu'une révolution française. Les puissances de l'europe ont trouvé le moyen d'en faire une révolution européenne. Au lieu de se borner à reconnaître le lieutenant général du royaume nommé par le roi, ce qui n'eût pas changé l'état politique de la France, ni celui de l'Europe, elles se sont empressées de reconnaître le nouveau roi des Français; c'était proprement le fair eroi sur la présentation de quelques ambitieux. Ce scandale dont leurs conseils [...] n'ont pas connu toute la portée, a rallumé en France ces passions que 15 ans de restauration avaient assoupies, ébranlé la fidélité des peuples, encouragé les révolutionnaires, et porté un coup mortel à toutes les royautés ${ }^{10}$.

Il popolo francese con la rivoluzione di luglio tentò di abbattere la monarchia, invece si ritrovò con un nuovo re (cugino di Carlo X) e con una nuova Carta costituzionale ( 9 agosto 1830) quasi fotocopia della Carta del 1814. L'innovazione sta nella concezione della monarchia e della Carta costituzionale. Si ritorna alla dottrina della "sovranità nazionale", la Costituzione è votata dal parlamento (quindi non octroyée) ed accettata dal re che assume il titolo di "re dei francesi" come Luigi XVI con la Costituzione del 1791. L'art. 14 della Carta del 1814, che consentiva al re di emettere ordinanze per supplire alle leggi e che aveva provocato la rivoluzione, fu sostituito dall'art. 13 il cui primo comma recitava:

Il Re è il capo supremo dello Stato, comanda le forze di terra e di mare, dichiara la guerra, fa i trattati di pace, d'alleanza e di commercio, provvede alle nomine per tutti gli impieghi dell'amministrazione pubblica e fa i regolamenti e le ordinanze necessarie per l'esecuzione delle leggi senza poter mai né sospendere le leggi stesse, né dispensare dalla loro esecuzione ${ }^{11}$.

Il re divide con il parlamento il potere legislativo (art. 15). Con la legge del 21 marzo 1831 furono disciplinati i consigli municipali, con

10. DE BONALD, Louis, Réflexions sur la révolution de juillet 1830 et textes inédits, Présentation et analyse de Jean Bastier, Paris, co-édition Duc-Albatros, 1988, p. 43.

11. SAITTA, Armando, Costituenti, op. cit., p. 291 
la legge del 19 aprile 1831 fu esteso il diritto di voto: per gli elettori il censo fu abbassato da 300 a 200 franchi e da 1000 a 500 per gli eleggibili. Nonostante questa riforma elettorale potevano votare circa l'1\% della popolazione. L'età per l'esercizio del diritto di voto fu portata da 30 a 25 anni. Con la riforma del 1831 la Camera dei pari divenne espressione dell'alta borghesia nobilitata dalla monarchia. La nomina dei membri spettò sempre al re, ma venivano indicate le categorie nell'ambito delle quali essi dovevano essere scelti. La Parìa non fu più ereditaria. Nel 1832, con la legge del 22 marzo, fu invece istituita la Guardia Nazionale, alla quale appartenevano tutti i cittadini che pagavano le tasse.

Ciò che conta veramente non è la Carta in sé, ma la prassi costituzionale che in base ad essa segnò l'avvio del c.d. "parlamentarismo orleanista". Durante la Restaurazione Luigi XVIII aveva inaugurato un percorso parlamentare (anche Luigi XVI mise in pratica il parlamentarismo quando, per esempio, destituì i ministri girondini dopo il voto ostile dell'Assemblea). Tuttavia, durante la Restaurazione, alla pratica parlamentare, mancano alcuni elementi caratterizzanti il regime parlamentare ortodosso: le camere non dispongono dello strumento dell'interpellanza che consente di esercitare il controllo dell'attività politico-amministrativa del governo; i partiti politici, in quanto strumenti per assicurare un collegamento reale con la società, non sono ancora costituiti; i ministri non formano ancora il "gabinetto" sotto l'autorità di un primo ministro o di un presidente del consiglio dei ministri; la responsabilità politica dei ministri di fronte alle Camere non è ancora considerata una procedura parlamentare definitiva; il capo dello Stato esercita il suo peso istituzionale per controbilanciare quello del parlamento.

Dopo la rivoluzione di luglio si affermeranno molti aspetti del parlamentarismo classico: si svilupperanno l'istituto dell'interpellanza, inizierà a funzionare l'istituto della responsabilità politica dei ministri, si affermeranno autorità del primo ministro e i partiti comincieranno ad organizzarsi. Ciò nonostante, la monarchia orleanista non si può considerare come regime parlamentare classico.

Agli inizi Luigi Filippo d'Orléans regnò secondo le regole del parlamentarismo, ma una volta consolidato il regime, governò personalmente. La monarchia di luglio è inquadrabile in una fase intermedia tra il regime parlamentare, dove il capo dello Stato svolge un ruolo simbolico, in quanto il potere esecutivo spetta al governo e al primo ministro, e la monarchia limitata nella quale il re esercita il potere esecutivo e il parlamento vota le leggi ed approva il bilancio. Nel parlamentarismo orleanista l'intervento del capo dello Stato attenua il carattere parlamentare. Scrive Humberto Nogueira Alcalá:

\begin{abstract}
El parlamentarismo de tipo orleanista se caracteriza por el derecho que posee el Jefe de Estado de revocar o hacer dimitir a sus ministros. Esta prerogativa permite al Jefe de Estado ejercer un poderoso medio de acción sobre gobierno o Gabinete responsable. El Jefe de Estado deja gobernar al consejo de ministros, pero lo controla; mas si pierde su confianza, lo aleja del gobierno, encargando éste a un nuevo equipo, con un programa más acorde a su punto de vista personal ${ }^{12}$.
\end{abstract}

Per concludere, si può parlare di un rapporto della doppia fiducia che lega $\mathrm{i}$ ministri al parlamento e al capo dello Stato. La rivoluzione di Luglio rappresenta il risultato di una nuova alleanza tra la borghesia finanziaria parigina ed aristocratici e borghesi possessori di grandi proprietà fondiarie. In definitiva, i rappresentanti dell'alta borghesia finanziaria riuscirono ad imporre il proprio disegno politico legittimando il nuovo regime attraverso la soluzione monarchico-costituzionale. La modesta revisione costituzionale, servì per rimediare agli eccessi assolutistici di Carlo X, garantire la Restaurazione e portare a compimento la prassi parlamentare.

\subsection{Costituzione belga del 1831}

La rivoluzione belga (scoppiata dopo la rivoluzione di luglio 1830 in Francia) fu il conflitto che portò alla secessione delle province del sud del Regno Unito dei Paesi Bassi e alla nascita del Belgio in quanto Stato indipendente (proclama del 4 ottobre 1830 con un decreto del governo provvisorio). Il 3 novembre 1830 si tennero le elezioni per il Congresso Nazionale che si riunì il 10 novembre. Il 18 novembre il Congresso confermò (votata all'unanimità) la dichiarazione d'indipendenza. Il 22 novembre 1830 il Congresso Nazionale optò per la monarchia costituzionale parlamentare ereditaria. Il 6 ottobre era stata istituita una Commissione incaricata di redigere la Costituzione; il testo del

12. ALCALÁ, Humberto Nogueira, Regimenes politicos contemporaneos, Santiago, Editorial Jurídica de Chile, 1993, p. 244. 
progetto costituzionale fu trasmesso al Governo provvisorio il 28 ottobre. Le sedute del Congresso iniziarono il 13 dicembre 1830 ad esaminare e modificare il progetto di Costituzione. Il 7 febbraio 1831 fu chiusa la discussione e il Congresso approvò la Costituzione belga.

La Costituzione belga, qua e là richiamata da non poche Costituzioni italiane, riprendeva molti principi ed istituti presenti nelle Costituzioni francesi del 3 settembre 1791, nella Carta del 4 giugno 1814 e nella Carta francese del 14 agosto 1830. Dicey non esitò a sostenere che il parlamento belga (si riferiva alle regole di funzionamento del sistema politico-costituzionale belga) aveva molti punti in comune con il sistema costituzionale inglese.

\section{Così scriveva:}

There is, it is said, a certain absurdity in bringing into one class things so different in importance and in dignity as, for example, the belgian parliament and an english schoool-board. This objection rests on a misconception. It would be ridiculous to overlook the profound differences between a powerful legislature and a petty corporation. But there is nothing ridicolous in calling attention to the points which they have in common. The sole matter for consideration is whether the alleged similarity be real. No doubt when features of likeness between things which differ from one another both in appearance and in dignity is pointed out, the immediate result is to produce a sense of amusement, but the apparent absurdity is no proof that the likeness is unreal or undeserving of notice. A man differs from a rat. But this does not make it the less true or the less worth noting that they are both vertebrate animals ${ }^{13}$.

Il testo formale belga del 1831, secondo Gilissen, è costituito per il 35\% delle sue norme dalla Carta francese del 1830 e da quella del 1815, circa il 10\% dalla Costituzione francese del 3 settembre 1791 e per il 40\% circa dalla Costituzione olandese del $1815 .{ }^{14}$ Dunque, anche la Costituzione belga del 1831 (non pochi studiosi hanno considerato la Costituzione

13. DICEY, Albert Venn, Introduction to the study of the Law of the Constitution, London, Macmillan and co. and New York, 1889, p. 87.

14.GILISSEN, John, Die belgische verfassung von 1831 - ihr ursprung und ihr einfluss, in W. Conze (Hrsg), Beiträge zur deutschen un belgischen verfassungsgeschichte im 19, Jahrhundert, Stuttgart, 1967, pp. 38-69. belga come modello di riferimento - insieme alle carte francesi - per alcune costituzioni italiane, in particolare per lo Statuto Albertino) non era un testo originale, con proprie specificità istituzionali, ma aveva mutuato molte norme da altre esperienze costituzionali.

La Costituzione ferdinandea del 1848, carta concessa, nel disegnare la meccanica costituzionale, attribuiva una posizione di privilegio al re rispetto a quella del parlamento, dunque il principio della "sovranità nazionale" cedeva rispetto a quello "monarchico" (la costituzione francese del 1830 e quella belga del 1831, invece, non erano carte concesse).

Il potere legislativo era esercitato dalla Camera dei Rappresentanti e dal Senato, che approvavano le leggi, e dal re, che aveva la funzione di ratifica e di promulgazione. Il corpo elettorale era su base censitaria; infatti coloro che avevano il diritto di voto per eleggere i deputati e i senatori erano solo i cittadini con mezzi economici sufficienti per pagare il "cens électoral". Il parlamento belga era considerato espressione della volontà nazionale, pur risultando eletto solo da una parte della popolazione. In realtà i membri delle due Camere erano i rappresentanti della minoranza che li aveva votati. Erano sostanzialmente espressione della borghesia, quindi rappresentavano soltanto quella minoranza che poteva per censo esprimere il diritto di voto. Il potere esecutivo era affidato al re e al Governo; è quest'ultimo tuttavia ad essere responsabile per la politica governativa. La Costituzione prevedeva che gli atti del Re sono efficaci solo se controfirmati da un ministro. I ministri rispondevano davanti alla Camera. Il controllo del potere esecutivo da parte del potere legislativo passava soprattutto dall'approvazione annuale del bilancio pubblico.

La forma di governo parlamentare non era prevista nel dettato costituzionale, si è instaurata nella prassi istituzionale con l'assunto che ogni atto del re avrebbe avuto la controfirma di un ministro (articolo 64 Cost.), sul quale si sarebbe trasferita la responsabilità dell'atto. Il Governo era comunque, politicamente responsabile di fronte al Parlamento (come diceva Dicey la Costituzione belga è "molto prossima alla riproduzione scritta della Costituzione inglese" ${ }^{15}$.

15. Costituzione del Regno del Belgio (7 febbraio 1831), in Costituzioni straniere contemporanee, Vol. I (a cura di) Paolo 


\subsection{La Costituzione del Regno delle Due Sicilie del 10 febbraio 1848}

A Palermo il 23 gennaio 1848 i quattro comitati deliberarono di costituire un Comitato Generale. Fu istituita la figura di un presidente e di un segretario generale, come presidente fu eletto Ruggero Settimo (28 voti contro 3), come segretario generale Mariano Stabile (all'unanimità) ${ }^{16}$.

Nel frattempo Ferdinando II, il 29 gennaio, pubblicava le basi della futura Costituzione poi promulgata il 10 febbraio 1848. Il testo costituzionale si basava sulla carta costituzionale francese del 14 agosto 1830. Essa è costituita in tutto da 89 articoli, di cui 31 sono dedicati alle disposizioni generali.

L'articolo 1 definisce la forma di governo del Regno delle Due Sicilie "temperata monarchia ereditaria costituzionale sotto forme rappresentative"17. Questa definizione la troviamo nell'articolo 2 della Costituzione di Baiona, ${ }^{18}$

Biscaretti di Ruffia, Milano, Giuffrè, 1989; interessante il lavoro di Letizia Rita Sciumbata, Un modello di Stato federale: il Belgio, in Istituto di Studi sui Sistemi Regionali Federali e sulle Autonomie "Massimo Severo Giannini" (ISSIRFA), disponibile su www.issirfa.cnr.it (Così scrive: La Costituzione belga rispecchia il quadro storico nel quale è stata elaborata, caratterizzato dal superamento della dottrina del legittimismo che le grandi potenze avevano tentato di restaurare al Congresso di Vienna del 1815. Con la rivoluzionaria separazione dal regno d'Olanda al quale il Belgio era annesso a seguito delle decisioni assunte dal Congresso di Vienna, si è affermato il principio della sovranità popolare e la richiesta, da parte del popolo con decisione autonoma, che a regnare sui belgi fosse la nuova dinastia d'origine germanica Sassonia-Coburgo. L'intenzione era quella di costituire un ordinamento monarchico e rappresentativo con un capo di Stato straniero in posizione di organo super partes. Il modello delineato con la Costituzione era quello $d i$ uno Stato accentrato con un forte potere esecutivo stabilito nella capitale. La Costituzione ha previsto, infatti, un Sovrano, capo dell'esecutivo e delle forze armate, con poteri effettivi nella nomina dei suoi ministri e competente a dirigere le relazioni internazionali e due Camere rappresentative, di cui una eletta direttamente dai cittadini (Camera dei Rappresentanti) e l'altra (Senato) parzialmente costituita con un procedimento di secondo grado. A livello periferico, la Costituzione ha previsto due categorie di enti territoriali: Province e Comuni, governati dai propri Consigli elettivi, ma controllati dai Prefetti....);

16. Collezione Officiale degli Atti del Comitato Generale di Sicilia nell'anno 1848, Palermo, nella Stamperia e Libreria di Antonio Muratori, Tipografo del Ministero della Giustizia, 1848, pp. 21-23. 17. il testo della Costituzione, in Le Costituzioni italiane (a cura di), AQUARONE, Alberto, D'ADDIO, Mario, NEGRI, Guglielmo, Milano, Edizioni di Comunità,1958, p. 565.

18. L'articolo 2 della Costituzione de Bayona de 1808 recita: "La Corona de las Españas y de las Indias será hereditaria en nuestra descendencia directa, natural y legítima, de varón en varón,por orden de primogenitura y con exclusiónperpetua de las hembras", in www.juntadeandalucia.es. nell'articolo 14 della Costituzione di Cadice del $1812^{19}$ (El Gobierno de la Nación española es una Monarquía moderada ereditaria), negli articoli 1 e 2 della Costituzione murattiana del 18 maggio 1815 e nell'articolo 14 del Regno delle Due Sicilie del 1820 (articolo identico a quello della Costituzione di Cadice del 1812).$^{20}$ L'articolo 4 attribuisce il potere legislativo al re e al parlamento (composto dalla camera dei pari e da quella dei deputati), stesso contenuto nell'articolo 14 della Carta costituzionale francese del 1830 e nell'articolo 26 della Costituzione belga del 1831 ('avverbio "collettivamente" utilizzato dal legislatore costituzionale francese e da quello belga è stato sostituito nella Costituzione ferdinandea dal sinonimo "complessivamente"). L'articolo 5 sul potere esecutivo è la traduzione dell'ultima parte dell'articolo 12 della Costituzione francese del 1830, mentre l'articolo 6 "L'iniziativa per la proposizione delle leggi appartiene indistintamente al re ed a ciascuna delle due Camere legislative" corrisponde alla prima parte dell'articolo 15 della Costituzione francese del 1830 ed alla prima parte dell'articolo 27 della Costituzione belga del 1831. Per ciò che riguarda l'interpretazione delle leggi la Costituzione napoletana sia per contenuto che per collocazione dell'articolo seguì l'art. 28 della Costituzione belga del 1831: l'interpretazione delle leggi in generale appartiene al potere legislativo ${ }^{21}$.

Con l'art. 87 (Talune parti di questa costituzione potranno essere modificate pe nostri dominii di là del Faro, secondo i bisogni e le condizioni particolari di quelle popolazioni) il legislatore costituzionale napoletano escluse per la parte continentale del Regno, la possibilità di una revisione della Costituzione, mentre l'ammise soltanto nei confronti della Sicilia, ancora una volta teatro di un'insurrezione. Questo articolo fu integrato dall'art. 32 della legge elettorale provvisoria per la prima convocazione della Camera dei deputati: "Ci riserbiamo di apportar delle modificazioni a questa nostra legge provvisoria elettorale per applicarla

19. il testo della Costituzione di Cadice, disponibile su www. dircost.di.unito.it.

20. i testi delle due Costituzioni, in Le Costituzioni italiane, op. cit., p. 382 e p. 467.

21. L'art. 3 del Codice civile napoletano stabiliva: " $E$ ' proibito $a^{\prime}$ giudici di pronunziare in via di disposizione generale o di regolamento nelle cause di loro competenza", in Codice per lo Regno delle Due Sicilie, Leggi Civili, Napoli, Stabilimento tipografico di Domenico Capasso, 1848, p.1. 
convenientemente a' bisogni ed alle speciali condizioni de' nostri reali dominii di là del Faro, tosto che avremo dato effetto a quanto trovasi disposto nell'articolo 87 della Costituzione"22.

La Costituzione napoletana si adeguò all'esempio della Costituzione francese del 1830, mentre l'art. 131 della Costituzione belga conteneva norme di revisione della Carta.

E' quindi una Costituzione flessibile e, come molte altre Costituzioni dell'800, non prevedeva un particolare procedimento di revisione, consentendo che ciò potesse avvenire attraverso l'ordinaria attività legislativa. Così scrivevano Francesco Racioppi e Ignazio Brunelli:

Perciocchè il nostro Statuto è di un epoca in cui si credeva che la miglior costituzione fosse quella che si può tutta comprendere sulle due faccie di uno scudo; la brevità, la generalità delle disposizioni, pareva allora il merito precipuo; come chi preferisse ai di nostri lo stile telegrafico delle dodici tavole, al fare ampio, concreto, minuzioso, dei codici moderni. Le costituzioni si concepivano piuttosto quali barriere al passato irrevocabile, anzichè regolamenti giuridici della futura azione degli organi pubblici; ond'erano piuttosto dichiarazioni e proclamazioni solenni di principii in attesa della loro sostanza vitale e specifica, anzichè leggi compiute in sè stesse, e pronte a funzionare senz' altro sussidio di sviluppi e determinazioni ulteriori ${ }^{23}$.

Nell'Ottocento prevaleva la supremazia della Legge, questa era espressione delle categorie sociali che partecipavano alla vita dello Stato. La Legge era fonte primaria del diritto e, in genere, la sottomissione alla Costituzione era solo apparente o formale. La Costituzione diventa "irrevocabile" nella parte in cui attribuisce la sovranità alla Legge. La ragione effettiva della flessibilità va ricercata nel carattere tendenzialmente "monoclasse" di molti Stati dell'Ottocento, nei quali l'egemonia era detenuta prevalentemente dalla borghesia e dalla componente aristocratica anche se in declino (il popolo era ancora escluso). Una Costituzione rigida, cioè non modificabile

22. Legge elettorale provvisoria per la prima convocazione della Camera de' Deputati, n. 61, del 29 febbraio 1848, in Collezione delle leggi e de' decreti Reali del Regno delle Due Sicilie, anno 1848, n. 3, p.95.

23.RACIOPPI, Francesco, BRUNELLI, Ignazio, Commento allo Statuto del Regno (con prefazione di Luigi Luzzatti), Vol. I, Torino, UTET, 1909, p. 194. con legge ordinaria, avrebbe potuto costituire una minaccia per l'esercizio del potere da parte della borghesia. L'oligarchia al potere (borghesi e in parte aristocratici) poteva disporre di tutti gli strumenti legislativi di volta in volta necessari per garantire l'ordine sociale se eventualmente messo in pericolo dall'elemento popolare, escluso dalla partecipazione alla vita delle Istituzioni Pubbliche.

In Sicilia il parlamento era ancora dominato in particolare dall'aristocrazia terriera, protagonista e alleata negli affari con commercianti e banchieri per lo sfruttamento delle terre, miniere o altre aziende. Non sempre i protagonisti del quadro socio-economico siciliano sono aristocratici di antico lignaggio, con essi si affacciavano commercianti, speculatori, esponenti di una borghesia alla ricerca di nobilitazione, molte delle quali arriveranno con l'Italia Unita.

Scrive Pinella Di Gregorio:

La più recente storiografia ha infatti messo in discussione la rigida divisione di ruoli tra grande proprietario assenteista e piccola e media proprietà imprenditrice, strozzata dalla permanenza dei residui feudali: contratti in natura, usura, gabelle e così via. Lo stesso proprietario terriero, pur se aristocratico, si comporterà da imprenditore o da percettore di rendita agraria in relazione alle fluttuazioni del mercato e alle opportunità ambientali secondo un modello che è stato definito di "azienda mista". Gli esempi in questo campo si moltiplicano: il barone Giuseppe Luigi Beneventano, che nel siracusano possiede un patrimonio fondiario di 14000 ettari, lo gestisce da imprenditore agricolo nelle zone agrume tate e da agrario latifondista nell'area coltivata a grano; il barone Niccolò Turrisi Colonna alla metà dell'Ottocento si dedica alla trasformazione della tenuta di Buonvicino in oliveto e vigneto, impiantandovi anche un allevamento di bovini; i baroni Pennisi di Floristella, moderni agrumicultori ad Acireale sono nel contempo rentier parassitari, in quanto proprietari di latifondo e di una miniera di zolfo a Castrogiovanni [...] L'ossessione per i titoli e le onorificenze dimostrata da Rocco Camerata Scovazzo [ex gabellotto di miniere zolfifere] è propria di un'élite di recente nobilitazione che, da una parte, aspira ad essere legittimata dal nuovo stato, dall'altra, attraverso ordini e prebende, tenta di definirsi come ceto per differenziarsi da strati sociali contigui [...] L'interesse politico dell'aristocrazia di antico lignaggio - una 
parte della quale aveva contribuito attivamente all'unificazione italiana - verso lo stato unitario non era dissimile da quello della nobiltà di più recente condizione. Vecchia e nuova aristocrazia, quindi, al di là di presunte barriere di status, sembrano muoversi in direzione dell'omologazione di una classe dirigente, in cui differenziazioni interne dipendono più da comportamenti individuali che da vincoli sociali [...] Nel primo ventennio postunitario la Destra storica tentò di costruire una classe dirigente nazionale, avendo come obiettivo una società oligarchica e censita ria. Pur in presenza di un suffragio ristretto, la camera era sempre elettiva; al contrario il Senato si prestava ad un'opera di ingegneria sociale attraverso cui creare, partendo da un ruolo che era politico e da un titolo, quello di senatore, una sorta di Camera alta mutuata dal modello inglese. In questo senso il Senato del Regno fu la rappresentazione vivente di ciò che l'Italia liberale riteneva fosse l'élite. I criteri di definizione erano "politici", giacché la rappresentatività non era data dalla rendita fondiaria (non tutti i grandi proprietari accedono al laticlavio), ma dalla cooptazione di quel ceto di possidenti nobili-notabili di cui il nuovo regime reputava di non poter fare a meno. I Moncada, i Morillo, i Paternò Castello o i Camerata Scovazzo, e soprattutto i Genuardi, provenivano da mondi diversi e seguivano, anche in età post-unitaria, percorsi socio-economici differenti; tuttavia, questi ed altri membri dell'aristocrazia siciliana sono accomunati dal fatto di essere stati nominati senatori, per la categoria di censo, dal governo liberale $\mathrm{e}^{24}$.

La camera dei deputati era composta da membri eletti in ragione di uno ogni 40 mila anime (art. 54), mentre l'art. 50 stabilendo che "i deputati rappresentano la nazione in complesso e non le province ove furono eletti" introduceva nell'ordinamento napoletano il principio del "divieto di mandato imperativo" che si ricollega immediatamente con quello della "sovranità nazionale". Il costituente francese nella Costituzione del 3 settembre 1791 ha inserito l'art. 7 (Titolo III, Capitolo I, Sezione Terza) che stabiliva: "I rappresentanti nominati nei dipartimenti non saranno rappresentanti di un dipartimento particolare, ma dell'intera Nazione,

24. DI GREGORIO, Pinella, Nobiltà e nobilitazioni in Sicilia nel lungo Ottocento, in Meridiana, Rivista di Storia e Scienze Sociali, n. 19, 1994, Roma, Casa Editrice Donzelli, pp. 107-111. e non potrà essere dato loro alcun mandato"25. La stessa disposizione la troviamo nell'art. 32 della Costituzione belga (I membri delle due Camere rappresentano la Nazione, e non soltanto la Provincia o la parte di Provincia che li ha eletti).

La Camera dei pari era composta da un numero illimitato di membri vitalizi nominati dal re tra i cittadini che avessero compiuto i trenta anni (artt. 43-45). Ai sensi dell'art. 48 la Camera dei pari, costituita in Alta Corte di giustizia, giudicava dei reati di altro tradimento e di attentato alla sicurezza dello Stato di cui fossero imputati i membri del Parlamento. Con l'art. 74, invece, si attribuisce alla Camera dei deputati il diritto di mettere in stato d'accusa i ministri, ma attribuisce la giurisdizione esclusivamente alla Camera dei pari ${ }^{26}$.

25. Nelle assemblee i membri rappresentavano i delegati della loro Comunità che davano loro precise istruzioni su come pronunciarsi sui vari argomenti da trattare. In questo contesto la rappresentanza esprimeva il rapporto tra rappresentante e rappresentato, secondo cui quest'ultimo, attraverso un atto di volontà chiamato "mandato imperativo", conferiva al primo il potere di agire nel suo interesse con l'osservanza dei limiti e delle istruzioni contenute nel "mandato". L'affermazione dello Stato liberale ha portato alla eliminazione dei corpi intermedi in questo modo dal punto di vista giuridico, la società si è presentata come formata da singoli individui eguali davanti alla legge. In questo modo, il rappresentante non era più espressione di "corpi" che non esistevano più, ma doveva agire nell'interesse generale. Ecco la grande trasformazione della rappresentanza. Da rappresentanza di interessi diventa rappresentanza politica, ovvero una situazione nella quale il rappresentante, adesso chiamato a perseguire gli interessi della nazione, non può essere soggetto a mandato vincolato. Questa trasformazione è avvenuta durante la rivoluzione francese. La Dichiarazione de diritti dell'uomo e del cittadino (1789) afferma, tra gli altri, un grande principio di organizzazione politica: quello della sovranità nazionale: "Il principio di ogni sovranità risiede essenzialmente nella Nazione. Nessun corpo o individuo può esercitare un'autorità che non emani espressamente da essa" (articolo 3). Questo principio fu inserito nell'articolo 1 (Titolo III) della Costituzione del 3 settembre 1791: " La sovranità è una, indivisibile, inalienabile e imprescrittibile. Essa appartiene alla Nazione; nessuna sezione del popolo, né alcun individuo può attribuirsene l'esercizio". Il principio della "sovranità nazionale", è stato elaborato per raggiungere scopi molto pratici, di natura politica. Se la sovranità non appartiene a monarca, come si sosteneva nell'antico regime, e non appartiene agli individui che compongono la società, come teorizzato da Jean-Jacques Rousseau viene allora trasferita alla "Nazione", questa considerata come un soggetto distinto dai cittadini che la compongono. Viene affermato un concetto di "Nazione" come persona giuridica distinta dai singoli individui che ne fanno parte, GRIMALDI, Angelo, La Costituzione siciliana del 1812, in Revista de Derecho, Vol. 48, julio-diciembre 2017, Barranquilla, División de Derecho, Ciencia Politica y Relaciones Internacionales de la Universidad del Norte, Colombia, pp. 220-222.

26. Si veda l'art. 47 della Costituzione francese del 1830 e la prima parte dell'art. 90 della Costituzione belga del 1831 che attribuiva alla Corte di Cassazione a Sezioni Riunite il giudizio sui ministri. 
Elettori ed eleggibili della Camera dei deputati erano i cittadini di 25 anni che non dovevano trovarsi in stato di fallimento o sottoposti a giudizio criminale (art. 55). L'art. 56 indicava i requisiti e le categorie sociali che avrebbero potuto esercitare il diritto di voto (cattedratici, industriali, professionisti, commercianti, ecc.). Al punto 1) è indicato il requisito censitario "tutti coloro i quali posseggono una rendita imponibile, di cui sarà determinata la quantità dalla legge elettorale".

L'art. 62 prevedeva per la prima convocazione della Camera una legge elettorale provvisoria "la quale non diventerà definitiva se non dopo essere stata esaminata e discussa dalle Camere medesime nel primo periodo della loro legislatura" (nel breve periodo della loro vita le due Camere non la resero mai definitiva).

La legge elettorale provvisoria per la prima convocazione della Camera dei deputati del 29 febbraio 1848, n. $61^{27}$ all'art. 2 stabiliva: "La quantità della rendita imponibile per essere compreso nelle liste [...], relativamente alla elezione de' Deputati, rimane determinata per gli elettori ad annui ducati ventiquattro, e per gli eleggibili ad annui ducati duecentoquaranta". Con il decreto del 5 aprile 1848 , n. $143^{28}$, art. 1 , comma 2, numeri 1,2,3 e 4, si accordava il diritto di voto "senza bisogno di censo, a cattedratici, industriali, commercianti, professionisti, laureati, membri ordinari di tutte le Accademie o Società scientifiche, letterarie ed economiche, mentre l'art. 13 dispone che tutte le norme della legge elettorale del 29 febbraio non abrogate dal decreto sarebbero rimaste in vigore. Nel preambolo si stabilì di ridurre il censo degli eleggibili a quello degli elettori.

Con questo decreto furono modificati gli articoli 56 e 57 della Costituzione. Era una Costituzione flessibile e, non prevedendo un particolare procedimento di revisione, consentiva che ciò potesse avvenire attraverso l'ordinaria attività legislativa. In questo caso però, a modificare la Costituzione era intervenuto un decreto del re. Si trattava di un decreto che nella gerarchia delle fonti esprimeva natura di atto

27. Collezione delle leggi e de' decreti Reali del Regno delle Due Sicilie, anno 1848, n. 3, pp.85-96.

28. Decreto portante delle riforme alla legge elettorale provvisoria, n. 143, del 5 aprile 1848, in Collezione delle leggi, cit., pp. 190-194. legislativo e non regolamentare. L'art. 2 della legge 24 marzo 1817 stabiliva la forma del decreto "in tutti quei casi ne' quali determineranno il modo di esecuzione delle leggi, l'applicazione e lo sviluppo de' principii fissati dalle medesime"29.

I decreti erano, nella gerarchia delle fonti, subordinati alle leggi, ma nonostante essi contenessero "lo sviluppo dei principi fissati nelle leggi", il loro contenuto non sempre era circoscritto a mere norme di esecuzione e di attuazione. $\mathrm{Nel}$ caso di specie, il decreto era riconducibile ai decreti con natura legislativa in quanto "atti d'autorità" (nel senso che il governo non doveva togliersi la facoltà di rimediare ai bisogni imprevisti e di facilitare l'esecuzione delle leggi, senza rischio di compromettere l'ordine e la sicurezza pubblica). I decreti c.d. "legislativi" spesso contenevano disposizioni che non si potevano facilmente ricondurre a semplici sviluppi di principi stabiliti nelle leggi formali e regolavano la materia in modo quasi interamente autonomo (mentre i regolamenti di amministrazione erano atti del potere esecutivo, potendo solo applicare ai singoli casi le disposizioni generali e le intenzioni delle leggi).

Durante l'Ottocento, in particolare dopo la Restaurazione, una corrente di pensiero sosteneva che il parlamento limitava il potere originariamente assoluto del re. Tale potere, limitato dalle leggi, ma non fondato dalle leggi, poteva agire in tutte quelle materie che la legge non aveva regolato. Questi ordinamenti assumono la forma di "monarchie limitate", in quanto l'assolutismo regio subì una trasformazione a causa dell'affermazione del diritto alla partecipazione all'esercizio della funzione legislativa da parte della borghesia, eletta su base censitaria in parlamento, garantito da una Costituzione al rispetto della quale il re si vincolava con giuramento. Però il sovrano conservava tutti i poteri prima posseduti non espressamente sottratti, e che di fatto rimanevano al di fuori del perimetro costituzionale. Questa presunzione di competenza ad emanare decreti con valore legislativo del re rappresentava in realtà un residuo della "plenitudo potestatis" goduta dal re nel periodo dell'assolutismo. Questa potestà residua, considerata la posizione

29. Decreto de' 24 marzo 1817 relativo alle attribuzioni del supremo consiglio di cancelleria ed alla sua organizzazione, in Le Leggi Amministrative del Regno delle Due Sicilie pe' dominj al di qua e al di la del Faro (per cura di Francesco Dias), Napoli, Tipografia de' Classici Italiani, 1845, p. 1249. 
di preminenza del re, attribuiva un carattere ineguale all'assetto dualistico di ripartizione del potere politico fra re e parlamento.

La persona del re, secondo l'art. 63 della Costituzione ferdinandea, era sacra ed inviolabile e non era soggetta ad alcuna specie di responsabilità. Il re convocava le sessioni annuali delle Camere, le prorogava, le chiudeva e poteva sciogliere la Camera dei Deputati, convocandone un'altra per nuove elezioni, entro un lasso di tempo improrogabile di tre mesi (art. 64). Ai sensi dell'art. 65 il re sanzionava le leggi votate dal parlamento, e se una legge a cui la sanzione reale veniva negata, non la si poteva richiamare in esame nella sessione dell'anno ${ }^{30}$.

I ministri erano responsabili solo di fronte al re (art. 71), potevano essere messi sotto accusa dalla Camera dei Deputati e giudicati dalla Camera dei Pari (art.74). Rappresenta la traduzione dell'art. 47 della Costituzione francese del 1830 e della prima parte dell'art. 90 della Costituzione belga del 1831 (la Camera dei rappresentanti ha diritto di accusare avanti alla Corte di Cassazione, che sola può giudicarli). Tutti gli atti di governo sottoscritti dal re non potevano avere effetto se non fosse stato controfirmato da un ministro segretario di Stato, "il quale perciò solo se ne rende responsabile" (art. 72) ${ }^{31}$. Quello della controfirma degli atti del re deriva dall'esperienza costituzionale inglese e rappresenta la conseguenza di due principi: il primo diceva che il re non può sbagliare (The King can do no wrong), il secondo sosteneva che il re non può agire da solo (The King cannot act alone), i sui atti dovevano essere ricondotti alla responsabilità di un altro soggetto. La controfirma di un ministro serviva quindi ad individuare un soggetto giuridicamente responsabile per gli atti compiuti dal re. L'istituto divenne uno strumento in mano al parlamento per far valere la responsabilità politica del governo nei suoi confronti e condizionare conseguentemente l'indirizzo politico del Gabinetto.

30. La prima parte dell'articolo è la traduzione dell'art. 18 della Costituzione francese del 1830 e dell'art. 69 della Costituzione belga del 1831, mentre la seconda parte proviene dall'art. 17 della Costituzione francese del 1830 e dall'art. 39 della Costituzione spagnola del 18 giugno 1837 (Si uno de los Cuerpos Colegisladores desechare algún proyecto de ley, o le negare el Rey la sanción, no podrá volverse a proponer un proyecto de ley sobre el mismo objeto en aquella legislatura).

31. Art. 64 della Costituzione belga del 1831: "Nessun atto del re può avere effetto se non è controsegnato da un ministro, il quale perciò solo se ne rende responsabile";
All'origine l'istituto della controfirma servì per superare il contrasto tra due grandi principi: quello che il re è soggetto alla "lex terrae" e quello che il parlamento non è organo sovrano. Senza la controfirma il parlamento avrebbe avuto la possibilità di controllare la conformità degli atti del re alla legge, e dunque avrebbe potuto rilevare la sua responsabilità. Se il parlamento avesse potuto esercitare il controllo sulla responsabilità del re avrebbe assunto una posizione di primazia rispetto a quella del re e sarebbe diventato il vero sovrano, l'altro principio escludeva che il parlamento potesse diventare organo sovrano.

La Camera dei Deputati, eletta il 18 aprile 1848, dopo le barricate del 15 maggio, in particolare in Via Toledo e in Via Santa Brigida (alla vigilia del 15 maggio 1848, mentre alcuni deputati tentavano di negoziare con il re per far modificare in parte la Costituzione, iniziarono a sorgere alcune barricate in città). La Camera dei deputati fu sciolta con decreto del 17 maggio il cui preambolo recitava: "Essendosi rilevato da documenti autentici, che nel disastroso giorno del 15 maggio coloro i quali erano stati eletti a far parte della Camera de' deputati si riunivano a vestir carattere di Assemblea unica rappresentante della Nazione, e si sceglievano un Presidente, e procedeano a delle deliberazioni, creando un Comitato di Sicurezza pubblica...."32. Con decreto n. 227 del 14 maggio 1848 si revocava il decreto del 5 aprile e la rendita imponibile per gli elettori veniva fissata a 12 ducati, mentre quella per gli eleggibili a 120 ducati (art. 2).

Dopo la convocazione dei collegi elettorali per il 15 giugno 1848, la Camera si riunì il 1 luglio 1848 e fu sciolta il 12 marzo 1849 (e mai più eletta). La Costituzione non fu revocata, rimase però quiescente e solo dopo l'atto sovrano del 15 giugno $1860 \mathrm{fu}$ richiamata ufficialmente in vigore con regio decreto 1 luglio 1860.

\section{FALLIMENTO DELLE TRATTATIVE E CONVOCAZIONE DEL PARLAMENTO GENERALE. RAPPORTO DELLA COMMISSIONE}

La nuova Costituzione napoletana prevedeva un unico Parlamento per il Regno delle Due Sicilie, i siciliani, invece, chiedevano la Costituzione del 1812 e un Parlamento separato per la Sicilia. Per

32. Decreto n. 221 del 17 maggio 1848, in Collezione delle leggi e de' decreti Reali del Regno delle Due Sicilie, anno 1848, pp.315-316. 
rispondere alle istanze siciliane la Costituzione conteneva l'art. 87 (Talune parti di questa Costituzione potranno essere modificate pe' nostri domini di là dal Faro, secondo i bisogni e le condizioni particolari di quelle popolazioni), il cui contenuto normativo fu completato con l'art. 32 della legge elettorale del 29 febbraio 1848 che così recitava: "Ci riserbiamo di apportar delle modificazioni a questa nostra legge provvisoria elettorale per applicarla convenientemente $a^{\prime}$ bisogni ed alle speciali condizioni de' nostri reali dominii di là del Faro, tosto che avremo dato effetto a quanto trovasi disposto nell'articolo 87 della Costituzione"33.

In questo breve periodo il Comitato Generale accettò la mediazione dell'ambasciatore straordinario inglese, Lord Minto, il quale aveva più volte insistito presso la Corte napoletana per il rispetto della Costituzione del 1812 da parte dei napoletani. Gaetano Falzone riporta una comunicazione di Lord Minto con il ministro degli Esteri inglese, Henry John Temple, $3^{\circ}$ Visconte di Palmerston: "Io giudico la sospensione della Costituzione del 1812 e lo stabilimento del governo assoluto in Sicilia come un atto illegale cui i siciliani hanno il diritto di ribellarsi" 34 .

La notizia di una mediazione inglese suscitò nel Comitato generale - in seno al quale era grande l'influenza di Mariano Stabile - il convincimento che la Sicilia avrebbe ottenuto con facilità il riconoscimento degli antichi diritti e il ripristino della Costituzione del 1812. Ruggero Settimo e Mariano Stabile rifiutarono la Costituzione concessa da re e riaffermarono la necessità di convocare il parlamento ed adattare ai tempi la Costituzione del 1812:

il voto universale di tutta l'isola è che il general Parlamento riunito in Palermo adatti ai tempi la Costituzione, che riformata sotto l'influenza della Gran Bretagna nel 1812, noi di diritto non abbiamo mai cessato di possedere. Le assicurazioni ricevute

33. Legge elettorale provvisoria per la convocazione della camera de' deputati de' 29 febbrajo 1848, $n .61$ (pubblicata il 1 marzo 1848), in Collezione delle leggi e de' decreti reali del Regno delle Due Sicilie, Anno 1848, Semestre I, Napoli, dalla Stamperia Reale, 1848, p. 95

34. FALZONE, Gaetano, Il problema della Sicilia nel 1848 attraverso nuove fonti inedite, Indipendenza e autonomia nel giuoco della politica internazionale, Palermo, A. Priulla Editore, 1951, p. 67. da Lord Minto ci fanno esser certi che il re di Napoli sia pronto a riconoscer gli antichi dritti della Sicilia, e la sua Costituzione del $1812^{35}$.

Il 24 febbraio 1848 il Comitato Generale di Palermo deliberò all'unanimità l'Atto di convocazione del General Parlamento di Sicilia (firmarono l'Atto 84 membri, ricordiamo, tra gli altri, Ruggero Settimo, Mariano Stabile, Pasquale Calvi, il trapanese Vincenzo Fardella, Marchese di Torrearsa, il Conte Giovanni Aceto, Giovanni Interdonato, Francesco Crispi, Rosolino Pilo, Giuseppe La Masa, Emerico Amari, Francesco Ferrara, Rosario Bagnasco, Giacinto Carini, Vito Beltrani, Vincenzo Errante, Gabriele Carnazza, ecc.).

L'Atto di convocazione era preceduto da un rapporto stilato da una Commissione che era stata incaricata di presentare un lavoro preparatorio sull'Atto di convocazione del Parlamento ed era composta da Pasquale Calvi (presidente), Vito Beltrani, Gabriele Carnazza, Francesco Ferrara, Emerico Amari (relatore). Nel rapporto sono rinvenibili importanti spunti e riflessioni di ordine giuridico che ci aiuteranno a comprendere pienamente non tanto l'Atto di convocazione quanto il testo dello Statuto costituzionale approvato dal Parlamento il 10 luglio 1848.

Il rapporto inizia con l'affermare la necessità di riunire una rappresentanza che fosse espressione dell'intera nazione: “...il primo bisogno d'un popolo libero è che questo governo sia l'espressione del voto nazionale, affinchè con mano severa ne concentri la forza, e l'apponga ai nemici della libertà..."36.

Il rapporto si sofferma sulla politica del governo napoletano:

La politica abituale napoletana, cioè di promettere e poi mancare, ha proclamato e tentato di fare svanire la mediazione, sperando negl'indugi. In tal

35. Risposta del Comitato Generale del 13 febbraio 1848, Bullettino n.55 che contiene una lettera di Lord Minto intorno alla Costituzione siciliana, e la risposta del Comitato generale, in Collezione Officiale degli Atti del Comitato Generale di Sicilia nell'anno 1848, Palermo, nella Stamperia e Libreria di Antonio Muratori, Tipografo del Ministro della Giustizia, 1848, pp. 104-106;

36. Rapporto della Commissione incaricata di presentare un lavoro preparatorio sull'atto di convocazione del General Parlamento di Sicilia, in Collezione Officiale degli Atti del Comitato Generale di Sicilia nell'anno 1848, Palermo, Nella Stamperia e Libreria di Antonio Muratori tipografo del Ministero della Giustizia, 1848, p. 147. 
caso la nazione Siciliana deve mostrare che ha una volontà e che ha forza pari alla volontà... ${ }^{37}$.

Dopo un breve accenno sulla opportunità di convocare il parlamento in concomitanza all'intervento di un mediatore, la relazione si sofferma sul potere, individuato in capo al Comitato Generale, di convocare il Parlamento:

A questi diversi sistemi si collega la questione del dritto, perché chi giudicasse che non si convochi il Parlamento secondo la Costituzione del 1812 potrebbe pensare che il Generale Comitato non ha dritto a convocare un parlamento, che secondo la Costituzione stessa dovea essere convocato dal potere esecutivo [...] Il Comitato ha fatto più che convocare un Parlamento, ha distrutto un governo che avea seppellito il Parlamento, o almeno l'avea condannato ad un perpetuo sonno; e senza ciò la stessa Costituzione prevede dei casi, in cui manchi il potere esecutivo, e il Parlamento o da se stesso si riunisce, o accorre alla voce di chi a nome della Nazione il primo l'invoca ${ }^{38}$.

A questo punto i relatori puntano sugli articoli della Costituzione del 1812 che consentirebbero al Parlamento in determinati casi di convocare il Parlamento, in questo sostituendosi al re, al quale invece, secondo l'art. 1 del Capo XI (Titolo I) spetterebbe il diritto di convocare il Parlamento (sarà unicamente dritto di S.M. quello di convocare, sciogliere e prorogare il Parlamento).

Sembra che i componenti del Comitato abbiano voluto dimostrare, citando gli articoli 9, $10,13,14,15$ e 24 (norme per la successione al trono del Regno di Sicilia), che la convocazione del Parlamento non da parte del re era in qualche modo riconducibile a fattispecie regolate dalla Costituzione del 1812. In questo modo, utilizzando una sorta di cerniera giuridica con cui congiungere gli atti e i fatti di un "presente rivoluzionario" con un "passato costituzionale", si voleva affermare e dimostrare che per i siciliani la Costituzione del 1812, formalmente non abrogata, non solo era ancora vigente, ma rappresentava un baluardo istituzionale del moto rivoluzionario.

Anche se era in corso una mediazione inglese, che aveva assunto come impegno preliminare che gli insorti accettassero il principio "dell'unione

37. Ibid., p. 148.

38. Rapporto della Commissione, op. cit., pp. 149-150. personale delle due corone", l'esperienza costituzionale siciliana del 1848, nonostante alcune importanti differenze, è riconducibile in qualche modo agli eventi rivoluzionari inglesi del 1660 dove vi fu una rottura della continuità dell'ordinamento istituzionale che fino a quel momento era stato dualistico, cioè si era retto sulla legittimazione dinastica del re e su quella del parlamento inteso come luogo di rappresentanza politica della nobiltà e borghesia.

\section{Così prosegue il rapporto:}

se non è riunito [il parlamento] dovrà subito riunirsi da sé; se si trova sciolto, forma da se un Parlamento nuovo. E vi ha dippiù; questo Parlamento nuovo così francamente e proprio jure riunito, ha poteri più estesi d'ogni altro; è vero parlamento costituente, perché l'art.26 [per la successione al trono] statuisce che s'è minore il re elegge la reggenza, fa la ricerca, corregge, riforma più esattamente che in ogni altro tempo tutti gli abusi che si fossero potuti introdurre durante il regno precedente, e finalmente provvede ad ogni altro bisogno dello Stato: se dunque può far tanto il parlamento senza il potere esecutivo, quando ancora si incarna in questo potere esecutivo non ha altra colpa se non d'essere lontano, incapace, o minore, che diremo quando il potere esecutivo dopo trentatre anni di tirannia, prima dichiara la guerra alla nazione, poi la bombarda, e finalmente l'abbandona? Ma fortunatamente la mano della Provvidenza sciolse il dubbio il giorno 12 gennaio 1848. Dunque la ragione ed il testo stesso della legge fondamentale fa evidente che vi è atto più santo, più legittimo, più costituzionale quanto convocare la rappresentanza della Nazione Siciliana ${ }^{39}$.

Il rapporto richiamava altresì formalmente gli articoli 9, 10, 13, 14, 24 e 25 (norme per la successione al trono del Regno di Sicilia) i quali disciplinavano i casi in cui il Parlamento avrebbe potuto eleggere il re o chiamare altro principe al trono di Sicilia. Fra le norme ricordiamo quella che disciplinava l'eventuale "elezione" di un sovrano non siciliano (doveva appartenere ad una famiglia reale e non doveva esercitare sovranità in un altro paese). Il nuovo sovrano, sin dalla sua elezione, avrebbe avuto la residenza in Sicilia e non si sarebbe potuto allontanare dal regno senza il consenso del parlamento. Il re che si fosse allontanato dal regno senza il consenso del parlamento, o che avesse prolungato

39. Rapporto della Commissione, op. cit., pp.150-151. 
la sua dimora fuori dalla Sicilia, oltre il tempo concessogli dal parlamento, non avrebbe potuto più regnare in Sicilia. Da quel momento sarebbe salito al trono un suo successore, se invece fosse stato senza successori, la Nazione avrebbe eletto il nuovo re. Sono da ricordare anche le norme che disciplinavano le funzioni del parlamento in caso di morte del re o quando il parlamento era stato sciolto dal defunto re ("i membri dell'ultimo Parlamento si uniranno da sé, e formeranno un nuovo parlamento" $)^{40}$.

I redattori del rapporto, rifacendosi al testo della Costituzione del 1812, cercarono di legittimare la convocazione del parlamento senza l'atto del re. Sono questi passaggi e queste scelte istituzionali che ci riconducono all'esperienza costituzionale inglese ${ }^{41}$.

40. Costituzione siciliana del 1812, Norme per la successione al trono del Regno di Sicilia, art. 25;

41. Il parlamento di Convenzione del 1660 trovò un appiglio giuridico nell'atto di convocazione effettuato da un parlamento che era stato regolarmente eletto, il long parliament, che emise le convocazioni sulla base delle disposizioni contenute nella legge triennale del 1641 che conteneva modalità sostitutive di convocazione in caso di assenza di volontà del re. Il Triennal Act del 15 febbraio 1641 fissava l'obbligo della durata massima delle assemblee per tre anni. Se entro tre anni dallo scioglimento il re non convocava un altro parlamento e nemmeno il Lord cancelliere vi provvedeva, i Pari si sarebbero riuniti di diritto. Restavano dodici mesi per emettere l'ordine di convocazione, in mancanza indicevano le elezioni gli sceriffi e gli altri componenti dei seggi elettorali. In caso di inutilizzo anche di quest'ultima facoltà, gli elettori si sarebbero riuniti come se l'ordine di convocazione fosse stato emesso. Si prevedeva inoltre, che nessun parlamento convocato con queste procedure straordinarie poteva essere sciolto senza il suo consenso prima di cinquanta giorni dalla data della prima riunione. Il parlamento del 1689, invece, non poteva confidare in quelle disposizioni in quanto l'Atto triennale del 1641 era stato abrogato e sostituito dal Triennal Act del 1664 che manteneva il principio della convocazione triennale del parlamento ma non prevedeva un meccanismo di salvaguardia che consentisse la convocazione dello stesso in assenza della volontà del re. Il 20 febbraio 1689 si provvedeva a sanare "a posteriori" l' illegittimità con un Atto di legalizzazione del parlamento (Recognition Act), sanzionato da Guglielmo e Maria, ormai sovrani. Si confermava così la successione al trono di Guglielmo e Maria e la validità delle leggi approvate dal parlamento Convenzione che era stato irregolarmente convocato. Il parlamento avrebbe potuto dichiarare la deposizione di Giacomo II, avendo il re violato la lex terrae, invece preferisce semplicemente dichiarare l'abdicazione. Evitando il parlamento di autoproclamarsi organo sovrano, pose le basi per l'affermazione dei principi necessari alla costruzione della monarchia costituzionale: rispetto delle libertà individuali, soggezione della Corona alla legge e alla volontà della Nazione espressa attraverso il parlamento. Sull'argomento si vedano, Parliamentary History, Statutes of the Realm, volumi 5 e 6, John Raithby Editor, 1819, pp. 226-234 e pag. 156, British History; HALLAM, Enrico, Storia costituzionale di Inghilterra, da cominciamento del Regno di Enrico VII alla morte di Giorgio II prima traduzione italiana dall'originale inglese del Barone Vito D'Ondes Reggio, Vol. IV, Torino, UTET, 1855, pp.5-157.
Nel rapporto si sostiene inoltre che il parlamento doveva essere espressione della nazione, del popolo. Si preferiva il bicameralismo all'assemblea unica, tipica dell'esperienza rivoluzionaria francese che, secondo i redattori, era considerata pericolosa per il buon funzionamento delle istituzioni costituzionali. Non resta che convocare il "Parlamento nazionale che si avvicini alle nuove esigenze sociali e ai dritti del popolo e che spingerà la rivoluzione nelle sue vie senza precipitarla". Si afferma che il popolo siciliano, per mezzo del Comitato, non avrebbe deposto le armi se non dopo aver riconquistato la sua Costituzione del 1812 e riformarla in alcuni punti.

I rivoluzionari siciliani avevano assunto, sin dal 1812, un comportamento "moderato"; più di una volta (nel 1812, ma anche nel 1820 nonostante la violenza iniziale) manifestarono interesse ad ottenere un risultato concreto, non ad uno sconvolgimento generale. I rivoltosi volevano ottenere riforme (moderate) costituzionali ed amministrative:

... e poi crediamo certamente atto più modesto del Comitato il dire al popolo Siciliano: V'invito a riunirvi in Parlamento con quelle riforme che la necessità ci suggerisce; anzichè dire, nulla più esiste, nulla, neppure la Costituzione che volte riformare [...] Rannodarci al nostro passato, riformare quanto comanda l'attuale urgenza, convocare una rappresentanza che dia sicure guarentigie, che possa riformare a seconda i bisogni del popolo, furono i tre principi che ci guidarono ${ }^{42}$.

Si volle (con scarsi risultati pratici) modificare la composizione sociale della Camera dei Comuni: "tutte le classi del popolo rappresentate, tutte le capacità trascurate nel 1812 [...] dovevano entrarvi [...] credemmo che doveano aver diritto a dare il voto elettorale otto larghe categorie, in vece dell'unica del censo considerata dalla Costituzione del 1812".

Si passa a stabilire i principi per l'elettorato passivo, cioè la capacità giuridica a ricoprire cariche elettive: "non vi è cittadino elettore che non possa entrar nella Camera dei Comuni". Si tratta di una affermazione formale di un principio democratico, in quanto l'art. 10 della Convocazione del General Parlamento recitava: "non potranno esercitare il diritto elettorale, tutti

42. Rapporto della Commissione, op. cit., p. 155; 
coloro che non sanno leggere e scrivere, giusto il Capo X della Costituzione, al Titolo "Libertà, Diritti e Doveri del Cittadino" (il Capo X recitava: "Ogni siciliano, per poter aver parte diretta o indiretta alla formazione della legge, dovrà saper leggere e scrivere, e così nel 1830 non sarà permesso ad alcun siciliano, che non sappia leggere, il poter essere elettore"). In questo modo, nonostante le roboanti affermazioni di principio, si esclusero dall'elettorato attivo e passivo, circa il 90\% della popolazione siciliana. Il Parlamento si sarebbe riunito il 25 marzo 1848 nella Chiesa di San Domenico.

Non ci sono dati ufficiali sul numero degli analfabeti nel 1848, alcuni autori riferiscono che alla vigilia dell'Unità d'Italia l'analfabetismo era pari all'88,6\% della popolazione ${ }^{43}$. Un dato ufficiale possiamo trarlo dalla statistica del 1909: in Sicilia la percentuale dei maschi analfabeti da 21 anni in su (per ogni 100 maschi da 21 anni in su) era del 64,9\%, (Palermo 57,1\%, Trapani $63,2 \%$, Messina 66,1\%, Catania 67,1\%, Siracusa $67,6 \%$, Girgenti 68,9\%, Caltanissetta 70,3\%) ${ }^{44}$.

Pochi giorni dopo Ferdinando II (6 marzo) pubblicava un decreto con il quale dichiarava di voler assicurare permanentemente la prosperità e le istituzioni parlamentari per i suoi sudditi siciliani, copiava fedelmente il proclama del Comitato Generale aggiungendo soltanto all'art. 1 le seguenti parole: "ferma rimanendo la dipendenza da unico Re per la integrità della Monarchia"45. Con un decreto istituiva e nominava Ministro Segretario di Stato per gli affari di Sicilia in Napoli il Commendatore Gaetano Scovazzo, mentre con un altro decreto (n. 74 del 6 marzo), al fine di provvedere in Sicilia "allo spedito andamento della sua amministrazione", il sovrano istituiva la carica di Luogotenente generale in Sicilia con tre ministri alla sua immediazione (dicastero di Grazia, Giustizia e Affari Ecclesiastici,

43. Nel 1820 il 90\% della popolazione del Regno delle Due Sicilie era analfabeta, sull'argomento si veda GENOVESI, Giovanni, Storia della Scuola in Italia dal Settecento a oggi, Bari, Laterza, 2004, p. 225.

44. Suffragio universale e analfabetismo, Appunti statistici, Vol. CLIII, Serie V-16 maggio 1911, pp. 333-334.

45. Art. 1: E' convocato in Palermo il general parlamento per adattare a' tempi ed alle politiche convenienze la Costituzione del 1812, e provvedere a tutti $i$ bisogni della Sicilia, ferma rimanendo la dipendenza da unico Re per la integrità della Monarchia, Atto sovrano n. 79 del 6 marzo 1848 in, Collezione delle Leggi e de' decreti reali del Regno delle Due Sicilie, anno 1848, n. 5, pp. 122-128.
Interno, Finanze). Il Luogotenente generale avrebbe trattato gli affari del Consiglio dei Ministri e si sarebbe dovuto rapportare con il Ministro degli Affari di Sicilia. La carica di Luogotenente generale veniva conferita a Ruggero Settimo, mentre all'avv. Pasquale Calvi veniva affidato il dicastero di Grazia, Giustizia e Affari Ecclesiastici, a Pietro Lanza, principe di Scordia, il dicastero dell'Interno e al trapanese Vincenzo Fardella, Marchese di Torrearsa, quello delle Finanze. Segretario del Consiglio dei Ministri fu nominato Mariano Stabile.

Il Re tentò di ricondurre alla sua volontà il contenuto delle scelte approvate dal Comitato generale $^{46}$ in modo da riportare la situazione sotto il suo controllo attraverso la figura del Ministro per gli Affari di Sicilia. Il disegno politico prevedeva, infatti, la nuova figura del Ministro per gli Affari di Sicilia (con residenza a Napoli), il quale avrebbe potuto, sulla base del suo mandato, esercitare il controllo sulle scelte politiche del governo presieduto dal Luogotenente generale. Nelle intenzioni del re una parte delle istanze dei ribelli siciliani si sarebbero potute guidare e riportare all'interno delle Istituzioni napoletane. Ancora una volta ${ }^{47}$ il Gabinetto napoletano cercò di riaffermare l'unità del Regno e la sovranità dell'unico monarca alle ripetute istanze politicocostituzionali siciliane.

Il Comitato generale, il 12 marzo avvisava che il giorno precedente aveva ricevuto un plico contenente i decreti del re: "il Comitato avendoli letti, ha immediatamente e all'unanimità riconosciuto che sono contrari alla Costituzione del 1812, e perciò li ha dichiarati come non avvenuti"48.

Proseguivano le trattative con lord Minto il quale consigliava di presentare delle controproposte (fermo restando il principio dell'unione personale delle due Corone). Le controproposte furono presentate: fu accettata l'unione personale delle due Corone (quindi unità del Regno e unico monarca), tuttavia dalle richieste dei siciliani (istituzione di

46. Si veda PELLERITI, Enza, 1812-1848. La Sicilia fra due Costituzioni, Milano, Giuffrè, 2000, p. LXXII.

47. GRIMALDI, Angelo, La Insurrección Siciliana de 1820. Aspectos Politico-Constitucionales, Revista de Estudios HistóricoJurídicos, n. 40, Escuela de Derecho, Pontificia Universidad Católica de Valparaíso, Chile, 2018, pp. 222-227.

48. Bullettino di notizie sul conto delle trattative col re di Napoli, in Collezione Officiale degli Atti del Comitato Generale di Sicilia nell'anno 1848, n. 91, cit., pp.219-220. 
un Vicerè, ministri responsabili di fronte al Vicerè, abolizione del Ministero per gli Affari di Sicilia a Napoli, conservazione della Guardia Nazionale, conservazione della bandiera, ecc.) emergeva un impianto incentrato sul riconoscimento di una maggiore autonomia amministrativa alla Sicilia nel rispetto dell'unità del Regno. In questo senso tali richieste sono coerenti con quelle avanzate 28 anni prima, con l'insurrezione di Palermo del $1820^{49}$.

Il governo napoletano il 22 marzo dichiarò nullo ogni decreto emesso del governo provvisorio della Sicilia ${ }^{50}$. Sull'argomento scriveva Simoncini Scaglione: "Commesso l'errore di pensare alla costituzione, quando il nemico era ancora nell'isola [...] bisognava riparare, rompendo ogni trattativa [...] in vece si prestava ascolto ancora alle parole di Lord Minto, il quale esortava si mantenessero sul medesimo capo le due corone, si rinunziasse al diritto della separazione assoluta che dava alla Sicilia la costituzione del 1812"51.

I collegi elettorali furono convocati il 15 marzo per i Comuni e il 18 per i distretti. Il Parlamento si riunì a Palermo il 25 marzo nella Chiesa di San Domenico. Esso era composto dalla Camera dei Comuni (150 membri), alla cui presidenza fu eletto il trapanese Vincenzo Fardella, Marchese di Torrearsa, mentre la Camera dei Pari (185 membri) elesse come presidente Domenico Lo Faso Pietrasanta, Duca di Serradifalco.

\section{PARLAMENTO SICILIANO DEL 1848 E POTERE COSTITUENTE}

Riunite le due Camere, il 26 marzo venne nominato Reggente della Sicilia, il Presidente del Comitato Generale Ruggero Settimo "con tutti i poteri e facoltà, che la Costituzione del 1812 accorda al Potere esecutivo"52. Al Presidente del Governo del Regno di Sicilia fu affidato il potere esecutivo, il quale lo eserciterà (art. 1 del decreto) per mezzo di sei ministri "da lui eletti, e da lui amovibili". Con Atto del 27 marzo Ruggero

49. GRIMALDI, Angelo, La Insurrección Siciliana de 1820, op. cit., 217-222.

50. ROMANO, Salvatore Francesco, Il '48 in Sicilia, in Il 1848, Raccolta di saggi e testimonianze, Roma, Quaderni di "Rinascita" a cura di G. Manacorda, $n .1$ del 1848, p.104.

51. SIMONCINI SCAGLIONE, Gaetano, Dal 48 al 60, op. cit., p. 44.

52. Collezione di Atti e Sessioni del general Parlamento di Sicilia colle leggi e decreti sancite dalle Camere Legislative, anno $1^{\circ}$ della Rigenerazione, Palermo, Dalla Stamperia Carini, 1848, pp. $13-23$.
Settimo nominò i sei ministri: Mariano Stabile agli Affari Esteri e al Commercio, il barone Pietro Riso alla Guerra e Marina (poi sostituito da Giuseppe Paternò, marchese di Spedalotto), il marchese Vincenzo Fardella alle Finanze (rinuncerà in quanto preferì restare alla presidenza della Camera dei Comuni, sostituito da Miche Amari), Gaetano Pisano al Culto e Giustizia, l'Avv. Pasquale Calvi all'Interno e Sicurezza Pubblica, Pietro Lanza, principe di Scordia e Butera, Duca di Branciforte e Camastra, all'Istruzione Pubblica e Lavori Pubblici ${ }^{53}$.

Il governo venne composto all'insegna della continuità, comprendeva i membri del Comitato Generale, a parte Pasquale Calvi, fu predominante la componente moderata ${ }^{54}$, per Giuseppe la Masa "gli uomini del potere esecutivo erano i medesimi capi settatori del principio moderato dell'Inglesismo e del privilegio" ${ }^{55}$.

Non pochi studios considerano il parlamento siciliano del 1848 come assemblea costituente, espressione quindi di potere costituente. Scrive Nino Cortese: "A differenza delle Costituzioni italiane [...] la siciliana, opera di due assemblee costituenti, ebbe una qualche originalità e merita particolare attenzione" ${ }^{\prime 56}$. Più cauto Vezio Crisafulli:

Non si arriva, certo, alla Repubblica, e nemmeno ad una vera e propria Costituente; tuttavia qualcosa di molto vicino al potere costituente trovò pratica realizzazione nel parlamento siciliano chiamato ad emendare e aggiornare la Costituzione del 1812, che era stata immediatamente rimessa in vigore dagli insorti... ${ }^{57}$.

Nel rapporto della Commissione incaricata di presentare un lavoro preparatorio si fa riferimento ad un vero parlamento costituente. Nella seduta del 2 giugno 1848 l'avv. Filippo Santocanale, a proposito del ruolo delle future Camere, disse: "Resta a determinare il carattere

53. Ibid., pp.30-33;

54. GEMELLI, Carlo, Storia della siciliana rivoluzione del 184849, Bologna, Giuseppe Legnani Editore, 1867, p. 49.

55. LA MASA, Giuseppe, Documenti della rivoluzione siciliana del 1848-49 in rapporto all'Italia, illustrati da Giuseppe La Masa Torino, Tipografia Ferrero e Franco, 1850, vol. primo, p. 223.

56. CORTESE, Nino, Introduzione alle costituzioni italiane del 1848-49, Napoli, Libreria Scientifica Editrice, 1959, pp. 100-101.

57. CRISAFULLI, Vezio, Profili costituzionali di una rivoluzione mancata, in Il 1848, Raccolta di saggi e testimonianze, Roma Quaderni di "Rinascita”, a cura di G. Manacorda, n. 1 del 1848, p.50. 
del Corpo legislativo della Sicilia: sarà esso sempre Costituente ${ }^{58}$. Sull'argomento Daniela Novarese scrive:

La domanda presupponeva, implicitamente, che l'Assemblea ritenesse di avere, in quel preciso momento storico, poteri costituenti, in quanto traeva legittimazione dalla rivoluzione popolare [...] L'assemblea che aveva redatto e votato la Costituzione, si assicurava, però, che il potere costituente non andasse perduto ${ }^{59}$.

Nel parlamento si erano formati anche su questo argomento diversi orientamenti. Erano dell'idea di non prolungare i lavori del parlamento "costituente", fino a ricomprendere l'emanazione delle leggi ordinarie attuative della Costituzione, tra gli altri, l'avv. Michele Bertolami e il barone Vito D'Ondes Reggio ai quali si contrapponevano, tra gli altri, l'avv. Filippo Cordova e l'avv. Giovanni Interdonato ${ }^{60}$.

Per assemblea costituente si intende generalmente un'assemblea eletta a suffragio ampio, incaricata di redigere una Costituzione. L'assembla costituente è quindi espressione di potere costituente. Il potere costituente si fonda sul principio della sovranità popolare, sul carattere contrattuale della Costituzione e sul diritto alla rivoluzione a tutela del diritto naturale preesistente allo Stato. Il potere costituente si legittima in via di fatto e si manifesta sopprimendo la precedente Costituzione, proponendone una nuova o modificando la vecchia Costituzione nei suoi principi fondamentali.

Nella vicenda costituzionale siciliana quarantottesca è mancato il suffragio universale

58. Le Assemblee del Risorgimento, Atti raccolti e pubblicati per deliberazione della Camera dei Deputati, Sicilia, Vol. I, Roma, Tipografia della Camera dei Deputati, 1911, p. 745;

59. NOVARESE, Daniela, Assemblee parlamentari e potere costituente in Sicilia (1812-1848) in, De curia semel in anno facienda. L'esperienza parlamentare siciliana nel contesto europeo (a cura di A. Romano), Atti del convegno internazionale di studi (Palermo, 4-6 febbraio 1999), Milano, Giuffrè, 2002, pp.144-146.

60. D'Ondes: "Tosto che lo Statuto or da noi decretato per l'accettazione ed il giuramento che ne farà il re avrà il vigore, o noi dovremmo dichiarare finita la nostra missione, o se dovessimo proseguire, essa si snaturerebbe, invece di Costituente, sarebbe quella di Parlamento ordinario"; Cordova:"...io non posso dubitare un momento che la nostra missione è nel tempo stesso costituente e legislativa..."; Interdonato: "Se noi continueremo da liberissima Costituente a compilare tutte altre leggi che rendono perfetta e finita l'opera cominciata..., in Le Assemblee del Risorgimento, Sicilia, Vol. I, op. cit., pp. 13, 15; maschile, il parlamento è stato eletto a suffragio ristretto e non ampio, non si può quindi indicare il "parlamento costituente" come espressione della sovranità popolare. Tuttavia, il parlamento del 1848 deriva da un evento rivoluzionario, da una rottura costituzionale che, nonostante le intense trattative diplomatiche con il re Ferdinando II per cercare di raggiungere un "accordo" sull'assetto istituzionale (autonomistico) da dare alla Sicilia, determinò, anche se non fu duraturo, l'inizio di un nuovo regime politico-costituzionale, cioè una nuova forma di governo.

I due principali attori costituzionali, nobili e borghesi, riproducono l'antico conflitto tra re e nobiltà feudale in Inghilterra, lo schema costituzionale ne è la prova evidente: indebolimento dei poteri del re anche oltre il disegno inglese.

Richiamare la Costituzione del 1812 nei "fatti" rivoluzionari servì per presentare il re come usurpatore dei diritti dei siciliani in essa contenuti (la legge fondamentale del Regno delle Due Sicilie dell' 8 dicembre 1816, recependo l'articolo 104 dell'Atto finale del Congresso di Vienna, stabiliva all'articolo 1 "Tutti i nostri dominj al di qua e al di là del Faro costituiranno il regno delle Due Sicilie"61. Quindi, si riunirono in un solo Stato i Regni di Napoli e di Sicilia con la nuova denominazione, il re assunse il titolo di Ferdinando I delle Due Sicilie. Con tale atto, tra l'altro, si privò la Sicilia della Costituzione promulgata nel 1812), e nello stesso tempo valido motivo per legittimare i fatti rivoluzionari e il conseguente sconvolgimento generale.

Si può parlare di rottura della continuità dell'ordinamento istituzionale (nonostante l'iniziale trattativa con il re), dove il sistema dualistico si interrompe temporaneamente $\mathrm{e}$ il parlamento per un breve periodo di tempo assume un ruolo di supremazia ed in quanto tale può essere considerato espressione di

61. Legge fondamentale del regno delle Due Sicilie dell'8 dicembre 1816, in Collezione delle leggi de' Decreti Reali del Regno delle Due Sicilie, numero 565, Napoli, Stamperia Reale, 1816, il cui preambolo recitava: "Il Congresso di Vienna nell'atto solenne a cui dee l'Europa il ristabilimento della giustizia e della pace, confermando la legittimità de' diritti della nostra corona, ha riconosciuto Noi ed i nostri eredi e successori re del regno delle Due Sicilie; Ratificato un tale atto da tutte le Potenze, volendo Noi, per quanto ci riguarda, mandarlo pienamente ad effetto, abbiamo determinato di ordinare e costituire per legge stabile e perpetua de' nostri Stati le disposizioni seguenti". 
potere costituente. La rivoluzione del '48, capeggiata da nobili e borghesi moderati, alla quale parteciparono, come nell'insurrezione di Palermo del 1820, gli strati popolari, poveri, piccoli artigiani, contadini, braccianti, donne "per la speranza di vedere in qualche modo migliorata la propria sorte" 62 , insieme all'opera del Comitato generale di Palermo e all'attività complessiva del parlamento generale, può essere considerata espressione di potere costituente.

La Camera dei Comuni il 31 marzo 1848 elegge 12 membri, che uniti all'altra Camera, dovevano formare il Comitato misto per le riforme della Costituzione del 1812 (furono eletti, tra gli altri, Michele Amari, Francesco Ferrara, Giovanni Interdonato, il barone Vito Ondes Reggio, il prof. Gregorio Ugdulena, l'avv. Gabriello Carnazza) ${ }^{63}$. La Camera dei Pari con votazione del 1 aprile elesse, tra gli altri, Monsignor Domenico Cilluffo, Romualdo Trigona, principe di Sant'Elia, Pietro Lanza, principe di Scordia e di Butera, Francesco Paolo Gravina, principe di Palagonia) ${ }^{64}$.

Nella seduta del 13 aprile 1848 la Camera dei Comuni approvò la dichiarazione di decadenza di Ferdinando di Borbone:

Il General Parlamento di Sicilia interprete dei voti della Nazione dichiara decaduto perpetuamente Ferdinando II Borbone, e tutta la sua dinastia [...] Ferdinando Borbone e la sua dinastia sono per sempre decaduti dal trono di Sicilia [...] Il Presidente invita la Camera a votare sulla mozione del signor La Farina [...] La Sicilia si reggerà a governo costituzionale, e chiamerà al trono un principe italiano dopo che avrà riformato il suo Statuto"65.

Il 2 giugno, il Comitato misto, presentò alle Camere un progetto di riforme degli articoli della Costituzione del 1812 (seguito da un rapporto illustrativo): 17 articoli che avrebbero dovuto costituire le basi della nuova Costituzione.

La preparazione e l'approvazione dello Statuto suscitarono un intenso dibattito parlamentare incentrato prevalentemente sugli aspetti

62. CRISAFULLI, Vezio, Profili costituzionali di una rivoluzione mancata, op. cit., p. 51.

63. Collezione di Atti e Sessioni del general Parlamento di Sicilia colle leggi e decreti sancite dalle Camere Legislative, cit., pp.75-83. 64. Ibid., pp. 84-85.

65. Ibid., pp. 311-312; giuridico-costituzionali della Carta. Si distinsero, tra gli altri, deputati come Francesco Ferrara, Vito d'Ondes Reggio, Francesco Paolo Perez, Gabriello Carnazza, Filippo Cordova, Michele Amari, Giuseppe Natoli, Giuseppe La Farina, Francesco Crispi, Pasquale Calvi. L’approvazione della Costituzione (10 luglio 1848) non fu semplice, esisteva nel parlamento bicamerale una profonda divisione tra i moderati liberali e i moderati repubblicano-democratici (Pasquale Calvi, Francesco Crispi, ecc.). Molti argomenti costituirono terreno di scontro e suscitarono aspre rivalità fra i deputati ${ }^{66}$.

\section{LO STATUTO COSTITUZIONALE DEL REGNO DI SICILIA (10 LUGLIO 1848)}

\subsection{Sovranità nazionale}

Nel 1848 lo Statuto siciliano fu l'unica carta costituzionale non ottriata, non concessa dal sovrano (dal francese octroyée), ma elaborata e votata da un parlamento eletto anche se a suffragio ristretto (votava ancora una minoranza, nobili, alta e media borghesia). Lo Statuto, approvato il 10 luglio 1848, è suddiviso in otto Titoli, questi in Capi, in tutto 98 articoli $^{67}$.

Iniziamo con l'art. 3 del Titolo I: "La sovranità risiede nella universalità dei cittadini siciliani: niuna classe, niun individuo può attribuirsene l'esercizio. I poteri dello Stato sono delegati e distinti secondo il presente Statuto". Si ritorna ad affermare la sovranità nazionale. Anche la Costituzione francese del 4 novembre 1848 all'art. 1 riafferma il principio della sovranità nazionale con la formula "la sovranità risiede nell'universalità dei cittadini francesi. E' inalienabile ed imprescrittibile. Nessun individuo, nessuna frazione del popolo può attribuirsene l'esercizio"68.

La Dichiarazione dei diritti dell'uomo e del cittadino francese del 1789 afferma, tra gli altri, un grande principio di organizzazione politica:

66. "...quel parlamento non altro fu che un calderone di disordini, di incertezze, di violente contrapposizioni interne", DI MATTEO Salvo, Storia dell'antico parlamento di Sicilia (1130-1849), Palermo, Graficreo, 2012, pp.97-98; si veda anche RIALL, Lucy, La Sicilia e l'unificazione italiana. Politica liberale e potere locale (1815-1866), Torino, Einaudi, 2004;

67 il testo dello Statuto Costituzionale del Regno di Sicilia del 10 luglio 1848, in Le Costituzioni italiane, op. cit., pp. 579-587;

68. SAITTA, Armando, Costituenti, op. cit., p. 323; 
quello della sovranità nazionale: "Il principio di ogni sovranità risiede essenzialmente nella Nazione. Nessun corpo o individuo può esercitare un'autorità che non emani espressamente da essa" (articolo 3). Questo principio fu inserito nell'articolo 1 (Titolo III) della Costituzione del 3 settembre 1791: " La sovranità è una, indivisibile, inalienabile e imprescrittibile. Essa appartiene alla Nazione; nessuna sezione del popolo, né alcun individuo può attribuirsene l'esercizio".

Se la sovranità non appartiene al monarca, come si sosteneva nell'antico regime, e non appartiene agli individui che compongono la società, come teorizzato dai democraticoradicali, viene allora trasferita alla "Nazione", questa considerata come un soggetto distinto dai cittadini che la compongono. Viene affermato un concetto di "Nazione" come persona giuridica distinta dai singoli individui che ne fanno parte. La Nazione, in quanto entità astratta, non poteva agire direttamente, di conseguenza doveva esercitare i suoi poteri per delegazione. In questo modo si evitano gli istituti di democrazia diretta ed il suffragio universale e si organizza un governo rappresentativo.

Dunque la "Nazione" è figura giuridica distinta dal re e dal popolo. Una volta affermato il principio rappresentativo, individuare il titolare della sovranità nella "nazione" in quanto persona giuridica unitaria (Costituzione del 3 settembre 1791, artt. 1 e 2 del Titolo III e art. 3 della dichiarazione dei diritti dell'uomo e del cittadino, nell' art. 2 della Costituzione del 5 fruttidoro anno III, più gli articoli 17 e 18 della dichiarazione dei diritti dell'uomo e del cittadino ${ }^{69}$ ) o nel popolo sovrano (Atto costituzionale del 24 giugno 1793, art. 7 e gli articoli 25 e 26 della dichiarazione dei diritti dell'uomo e del cittadino ${ }^{70}$ ) significa individuare un principio di legittimazione "dal basso" sul quale basare il fondamento del potere politico nel consenso dei soggetti governati. Nel caso siciliano ancora una volta il consenso investiva sicuramente una parte molto piccola dell'elemento popolare (solo l'alta e media borghesia) di conseguenza, risulta difficile individuare un principio democratico e considerare il parlamento quale espressione della "universalità dei cittadini siciliani" (ma non del popolo).

69. SAITTA, Armando, Costituenti, op. cit., p. 71, p. 121; 70. Ibid., p. 154;
Nella "sovranità popolare" ogni individuo è considerato il detentore di una frazione di sovranità: "nessuna parte del popolo può esercitare il potere del popolo intero; ma ogni sezione del sovrano riunito in assemblea deve godere del diritto di esprimere la sua volontà con una completa libertà". Più esplicito l'art. 25 della Dichiarazione dei diritti: "La sovranità risiede nel popolo; essa è una e indivisibile, imprescrittibile e inalienabile"71. Vezio Crisafulli sostiene, invece, che nell'art. 3 dello Statuto siciliano si ritrova il principio della sovranità popolare: "il principio democratico della sovranità popolare trova esplicito accoglimento nell'articolo 3, insieme con la guarentigia liberale della distinzione $(\mathrm{e}$ non della divisione o, peggio, separazione) dei poteri"72. Anche Daniela Novarese considera il Parlamento siciliano espressione della sovranità popolare $^{73}$, mentre Enza Pelleriti afferma:

Particolare attenzione merita, poi, quella che a prima vista può considerarsi una soddisfacente vittoria della sinistra liberale e dei democratici, ovvero l'introduzione nello Statuto del 1848 del principio della sovranità popolare, innovazione di grande portata rispetto al testo del '12, che sembrava catapultare la Carta siciliana nell'orbita del costituzionalismo rivoluzionario di matrice francese $\mathrm{e}^{74}$.

L'art. 1 ("La religione dello Stato è la Cattolica apostolica romana. Quando il re non vorrà professarla, sarà ipso facto decaduto") sembra riportare, a parte la diversa fede religiosa, all'esperienza costituzionale inglese. Infatti, l'Act of Settlement (approvato dal parlamento inglese nel 1701) conteneva disposizioni di rango costituzionale per la successione al trono nella linea protestante, i sovrani inglesi dovevano essere di fede anglicana ${ }^{75}$ (ciò per non mettere in pericolo i successi della "Gloriosa rivoluzione").

71. Art. 26 della Dichiarazione dei diritti dell'uomo e del cittadino, Atto Costituzionale del 24 giugno 1793, in SAITTA, Armando, Costituenti, op. cit., p.120

72. CRISAFULLI, Vezio, Profili costituzionali di una rivoluzione mancata, op. cit., p.51;

73. "I nodi da sciogliere riguardavano, piuttosto, la durata e i compiti della Costituente, le funzioni del futuro Parlamento, espressione della sovranità popolare, nonché la dialettica Sovrano-Parlamento", NOVARESE, Daniela, Assemblee parlamentari e potere costituente in Sicilia (1812-1848), op. cit., p. 144;

74. PELLERITI, Enza, 1812-1848. La Sicilia fra due Costituzioni, op. cit., p.XCIII;

75. The Act of Settlement of 1701 was designed to secure the Protestant succession to the throne, and to strengthen 
Con l'art. 2 (La Sicilia sarà sempre Stato indipendente. Il re de' Siciliani non potrà regnare o governare su verun altro paese. Ciò avvenendo, sarà decaduto ipso facto. La sola accettazione di un altro principato o governo lo farà incorrere ipso facto nella decadenza) si voleva impedire che il re fosse al tempo stesso capo di un altro Stato, quindi evitare l'unione personale delle due corone (l'art.62 della Costituzione belga del 1831 riporta la stessa disposizione).

\subsection{Parlamento, elezioni e potere legislativo. Bicameralismo quasi paritario. Esame comparato (Francia, Stati Uniti)}

Il potere di fare le leggi, interpretarle e derogarle spetta esclusivamente al Parlamento (diviso in due Camere, una dei deputati e l'altra dei senatori), "composto dai rappresentanti del popolo". Come esposto prima, pochi erano gli elettori, solo l'alta e media borghesia, di conseguenza, risulta difficile considerare il parlamento quale espressione del popolo. I membri del parlamento non erano eletti dal popolo ma da una ristretta base elettorale (suffragio universale maschile in senso formale ma con le correzioni - requisito della capacità di saper leggere e scrivere - si trasformò a suffragio a base ristretta, nel 1848 gli analfabeti costituivano poco meno del $90 \%$ della popolazione) ed in quanto tali non potevano essere considerati diretta espressione della sovranità popolare (gli eletti rappresentavano prevalentemente gli interessi dell'élite che li aveva votati). Venne rimosso il limite del censo, previsto dalla Costituzione del 1812 , ma fu inserito il requisito della capacità di leggere e scrivere.

Un aspetto di grande rilievo costituzionale, che si collega al concetto di sovranità nazionale, è disciplinato dall'art. 18: "I membri del Parlamento rappresentano l'intiera Sicilia, non i comuni o i distretti dai quali sono eletti". Se i parlamentari rappresentavano l'intera Sicilia, essi non dovevano curare gli interessi particolari dei loro comuni o dei loro distretti (collegi elettorali), bensì l'interesse nazionale. Questo articolo implicitamente introduce il divieto di mandato imperativo, quindi vieta la rappresentanza per interessi per affermare

the guarantees for ensuring a parliamentary system of government, disponibile su www.royal.uk/act-settlement-0; il testo anche in www.legislation.gov.uk. la rappresentanza politica: se il parlamentare doveva curare l'interesse generale, non doveva essere vincolato da istruzioni ricevute dagli elettori. L'art. 15, però, consentendo ai Comuni di pagare l'indennità ai rappresentanti avrebbe potuto in qualche modo inficiare il concetto affermato all'art. 18 , in quanto avrebbe potuto legare gli eletti ai Comuni. Per la Costituzione americana, invece, i Senatori e i rappresentanti "riceveranno un compenso per i loro servizi, da determinare per legge e da pagare a carico del Tesoro degli Stati Uniti" (art. I, sez. 6; si veda anche l'art. 38 della Costituzione francese del 1848).

La rappresentanza politica non presuppone un rapporto tra il rappresentante e il rappresentato, in quanto il rappresentante rimane autonomo rispetto all'elettore (dovendo curare gli interessi generali). Dalla lettura degli articoli 5, 13, 18, 26, 27 e 33 sembra che il parlamento siciliano si sia ispirato solo in parte alla Costituzione degli Stati Uniti d'America del 1787, mentre, a causa di alcune vicende politico-costituzionali siciliane, se ne allontanò nel contenuto con gli articoli 15, 28 e 30.

L'art. 18 dello Statuto siciliano è simile al contenuto dell'art. 34 della Costituzione belga (i membri delle camere rappresentano la nazione e non unicamente la provincia o la suddivisione di provincia che li ha nominati) e dell'art. 34 della Costituzione francese del 4 novembre 1848 (I membri dell'assemblea nazionale sono rappresentanti, non del dipartimento che li nomina, ma della Francia intiera), per certi versi l'art. 3 riprende anche il contenuto dell'art. 25 della Costituzione belga. L'art. 19 della Costituzione francese (La separazione dei poteri è la prima condizione di un governo libero) è molto simile al secondo periodo dell'art. 3 dello Statuto siciliano (da ricordare anche l'art. 35 della Costituzione francese sul divieto di mandato imperativo con l'art. 97 dello Statuto siciliano anche se riferito al Senato).

Non pochi studiosi hanno sostenuto che i siciliani subirono l'influsso della rivoluzione parigina del $1848^{76}$ o di quella belga del 1831; ciò

76. "Senza dubbio, $i$ costituenti siciliani subirono l'influsso della rivoluzione parigina del febbraio 1848; forse si avvalsero del primo progetto di Costituzione che [...] una Commissione appositamente nominata aveva preparato per la nuova repubblica francese e del quale aveva dato notizia l'ufficiale Moniteur del 20 giugno...,", CORTESE, Nino, Introduzione alle Costituzioni Italiane del 1848-49, Napoli, Libreria Scientifica 
è parzialmente vero, alcuni articoli, ed altri ancora, sono simili ed introducono nell'ordinamento gli stessi principi giuridici. Tuttavia, la Costituzione siciliana disegna una forma di governo, anche se solo in parte e in modo non lineare, riconducibile alla Costituzione americana del 1787 (quest'ultima si ispirava all'esperienza e alle regole di funzionamento della monarchia costituzionale inglese) e alla Costituzione francese del 1848. Analizzeremo più avanti la trama costituzionale siciliana in rapporto a quella americana, inglese e francese (il contenuto degli articoli 47 e 51 della Costituzione belga, che disciplinano i requisiti per accedere alla Camera dei Rappresentanti e la durata della Camera, sono diversi dalla disciplina siciliana; ancora, l'art. 55 della Costituzione belga "I senatori sono eletti per otto anni; essi sono rinnovabili per metà ogni quattro anni, nell'ordine determinato dalla legge elettorale. In caso di scioglimento il Senato è rinnovato integralmente" è diverso dall'art. 33 della Costituzione siciliana).

Nella tradizione costituzionale americana la rappresentanza generale è sempre stata collegata alle elezioni. Leggiamo un passaggio del numero 57 del "The Federalist":

...Tutti questi argomenti, tuttavia risulterebbero insufficienti senza il controllo di elezioni frequenti. Quindi, in quarto luogo, la Camera dei Rappresentanti è così costituita da far sentire ai membri un ricordo abituale della loro dipendenza dal popolo. Prima che i sentimenti impressi nelle loro menti nel momento delle elezioni possano esser cancellati dall'esercizio del potere, essi saranno costretti ad anticipare il momento in cui il loro potere dovrà cessare, quando il loro esercizio dovrà essere rivisto e quando essi dovranno "discendere" al livello dal quale sono stati innalzati; là rimarranno per sempre a meno che un fedele espletamento del loro mandato costituisca titolo per un rinnovo dello stesso ${ }^{77}$.

Gli elettori potranno far valere la responsabilità dell'eletto nella successiva tornata elettorale non eleggendolo più. Emerge, quindi, l'aspetto della rappresentanza come rapporto, ma non si tratta di un ritorno alla rappresentanza per interessi (manca il mandato vincolato).

Editrice, 1959, p. 101

77. The Federalist no. 57, New York Packet, Tuesday february 19, 1788, James Madison, disponibile su https://constitution.org.
$\mathrm{Si}$ passa dalla responsabilità giuridica alla responsabilità politica; l'eletto, politicamente responsabile, rimane giuridicamente autonomo rispetto all'elettore, il quale però detiene il potere "politico" (non giuridico) di valutare l'eletto al termine del mandato, di conseguenza l'elettore potrà rivotarlo, consentendo eventualmente (in caso di voto generalizzato) la conferma nell'incarico, oppure, in caso di giudizio negativo, far ritornare a vita privata il candidato.

Con gli articoli 13 e 33 e 95 lo Statuto siciliano segue lo schema del Congresso degli Stati Uniti (art. 13: "l'ufficio dei deputati durerà per due anni, quello dei senatori per sei. Gli uni e gli altri potranno essere rieletti; art. 33: "La Camera dei deputati si rinnoverà per intero, quella dei senatori per terzo, in ogni biennio"; art. 95: "nella prima sessione i senatori si divideranno a sorte in tre classi. La prima durerà per due anni, la seconda per quattro, la terza per sei") ${ }^{78}$. Per quanto riguarda, invece, le norme di revisione della Costituzione (art. 94), il testo si accosta a quanto aveva disciplinato la Costituzione belga del 1831 con l'art. 131(il testo siciliano non prevede l'accordo con il re): lo Statuto si sarebbe potuto modificare solo dopo una precisa dichiarazione di riforma del parlamento. Si sarebbe dovuto sciogliere il parlamento, indire nuove elezioni, quindi riunione della nuova legislatura. La delibera iniziale che avrebbe proposto la riforma e la proposta di riforma del nuovo parlamento sarebbero state efficaci se adottate a maggioranza dei $2 / 3$ dei votanti presenti in ciascuna Camera (Camera dei deputati e Camera dei senatori).

Negli Stati Uniti l'organo legislativo è il Congresso, composto di due Camere: la Camera dei Rappresentanti e il Senato. I membri della Camera dei Rappresentanti sono eletti direttamente dal popolo (art.1, sezione 2: "La Camera dei Rappresentanti sarà composta si membri scelti ogni due anni dal popolo dei diversi Stati..."), mentre il Senato è composto di due senatori per ogni Stato (art. 1, sezione 3: "Il Senato degli Stati Uniti sarà composto da due senatori per ciascun Stato [...] per sei anni [...] Immediatamente dopo che si saranno riuniti a seguito delle prime elezioni, essi saranno divisi nel modo più uniforme possibile in tre classi. I seggi dei senatori della prima classe si riterranno vacanti allo scadere del secondo anno, quelli della seconda

78. l'art. 95, in Le Costituzioni italiane, op. cit., p. 587; 
classe allo scadere del quarto anno e quelli della terza classe allo scadere del sesto anno, in modo tale che un terzo sarà eletto ogni due anni...") $)^{79}$. La Camera dei rappresentanti ha una durata di due anni in ossequio all'ideale democratico, era ed è considerata la più diretta espressione del popolo. In Sicilia, invece, avendo la Costituzione attribuito il diritto di voto ad una minoranza, i deputati non potevano considerarsi diretta espressione del popolo, ma della minoranza che li aveva votati (aristocratici ed alta e media borghesia).

Nel sistema americano, il giudizio elettorale a breve scadenza era ed è legato al principio di rappresentanza inteso come rapporto, le cui dinamiche sono state prima esposte, ma nel sistema siciliano del '48, a ristretta base elettorale, tra l'eletto (o il candidato) e gli elettori, entrambi espressione della stessa classe o gruppo sociale, non si sarebbe potuto esercitare il "potere politico" attraverso cui i secondi avrebbero potuto valutare il primo al termine del mandato. Seguendo l'esempio nord-americano si introdusse un elemento di debolezza, questa, dovuta essenzialmente alla breve durata della Camera dei deputati e al conseguente precario indirizzo politico conseguibile.

Il Senato americano ha una durata di sei anni e rinnovabile di $1 / 3$ dei suoi membri ad intervalli di due anni, probabilmente in contemporanea alle elezioni per la Camera dei Rappresentanti. Nel caso siciliano una maggiore durata del Senato, che avrebbe assicurato allo stesso continuità di indirizzo politico, sarebbe servita per far assumere una tendenza conservatrice nell'orientamento generale del parlamento dato che, come vedremo più avanti, esso non era caratterizzato da un bicameralismo pienamente "paritario" (negli Stati Uniti, invece, era conseguenza logica del principio federale).

Per la Costituzione del '48 la Camera dei deputati e quella dei senatori hanno identica posizione ed identici poteri (art. 26). Questo profilo è espresso nel procedimento di approvazione di una legge: discussa ed approvata da una delle due Camere, il testo viene trasmesso all'altra, se questa la rigetta o apporta modifiche ad alcune parti, potrà intervenire una deputazione mista o commissione bicamerale, composta in

79. il testo della Costituzione degli Stati Uniti d'America disponibile su www.senate.gov. egual misura da deputati e senatori (negli Stati Uniti Conference Committee), che ha il compito di ricercare un compromesso cercando di conciliare le differenze e ridurre le Camere alla conformità dei voti (art. 27). Il nuovo progetto di legge sarà presentato alla discussione delle Camere. Ove questo nuovo tentativo risultasse difficile, il progetto di legge si sarebbe dovuto considerare definitivamente respinto ("una proposta definitivamente rigettata non può riprodursi che alla nuova sessione", ultimo periodo dell'art. 27).

Esiste un'eccezione al principio dell'identità dei poteri: alla sola Camera dei deputati spettava l'iniziativa delle leggi in materia finanziaria, la Costituzione siciliana all'art. 28 attribuisce al Senato "il diritto di assentire o dissentire, senza farvi modificazioni" (mentre il Senato americano poteva presentare proposte o concorrere con emendamenti come per gli altri progetti, art. 1 , sezione 7 Costituzione americana). Sono essenzialmente due i motivi di un bicameralismo quasi paritario (che non compromette la reciproca parità di posizione). Uno potrebbe essere ricondotto alla maggiore durata (sei anni) della Camera dei senatori rispetto a quella dei deputati, e quindi l'art. 28 come contrappeso alla stabilità dell'indirizzo politico perseguibile dalla Camera dei senatori rispetto a quello precario della Camera dei deputati. L'altro, sarebbe riconducibile alla composizione socio-economica delle Camere. Su questo argomento intervenne in modo decisivo il barone Vito D'Ondes Reggio nella seduta del 10 luglio 1848:

Il popolo, si dice,elegge i deputati ed i senatori: ma i primi rappresentano il popolo, perché non si ommette alcuna categoria sulla loro eleggibilità; non così per i secondi, i quali non sono figli di una pura rappresentanza, giacchè il censo è ritenuto. Inoltre questa Camera ha confermato Pari a vita tutti coloro che vengono chiamati alla Parìa dalla Costituzione del 1812, e che personalmente firmaron l'atto del 13 aprile; ecco quindi un altro elemento non popolare. Più ai senatori si diede la durata di sei anni, mentre ai deputati si accordò la brevissima durata di anni due. Ecco quante differenze; quindi se il popolo è quello che paga l'imposta, è ben giusto che i Pari debbano accettare quella legge che danno i veri rappresentanti del popolo ${ }^{80}$.

80. Le Assemblee del Risorgimento, Atti raccolti e pubblicati per deliberazione della Camera dei Deputati, Sicilia, Vol. I, Roma, Tipografia della Camera dei Deputati, 1911, p. 1142; sul punto si 


\section{IL RE NON E' UNO DEI TRE ORGANI LEGISLATIVI. VETO SOSPENSIVO E PROMULGAZIONE DELLA LEGGE. ESAME COMPARATO (STATI UNITI, FRANCIA E INGHILTERRA)}

L'art. 30 (La legge fatta dal Parlamento sarà nello spazio di trenta giorni promulgata dal re o con apposite osservazioni rimandata al Parlamento. Quante volte nella sessione immediata a quella in cui la legge fatta il Parlamento vi persista, il re fra quindici giorni dovrà necessariamente promulgarla) va letto alla luce degli articoli prima commentati e con gli articoli 29, 34, 51, 52, 53, 67, 68 e 69. Il re è il capo dell'Esecutivo, le funzioni di governo sono esercitate dal re, cioè sotto i suoi ordini, diretti o indiretti, per mezzo dei ministri responsabili e da lui scelti.

Il re non avrebbe potuto esercitare i poteri a lui delegati dalla Costituzione senza aver prima consultato il Consiglio dei Ministri (art. 54). A parte l'art. 54, nel quale il Consiglio dei Ministri viene solo menzionato, non c'è nel testo una disciplina dell'organo costituzionale "Consiglio dei Ministri", nemmeno nel Capo II (Dei Ministri). I ministri, non solo sarebbero stati individuati e scelti dal re, ma quest'ultimo avrebbe potuto esercitare il potere di revoca (elezione e revocazione).

L'ultimo periodo dell'art. 29 recita: "I ministri possono presentare e discutere progetti di legge". Nella seduta della Camera dei Comuni del 24 giugno 1848 il testo era il seguente: "Al Re appartiene del pari la iniziativa della legge, questi la eserciterà per mezzo dei suoi ministri..... Dopo gli emendamenti (proposti da Marocco ed Errante) di sostituire "al Re appartiene" con "ai ministri appartiene, si pervenne al testo definitivo: "I ministri possono presentare e discutere i progetti di legge" ${ }^{\prime 1}$. Quindi il re, anche indirettamente, per mezzo dei suoi ministri, avrebbe partecipato alla funzione legislativa. Dobbiamo per prima cosa distinguere i poteri, diretti e indiretti, del re nei confronti del parlamento. Il re, secondo il testo costituzionale adottato, non ha un potere personale d'iniziativa legislativa. Dunque, si potrebbe accogliere il principio che afferma l'inesistenza di un diritto

veda anche CORTESE, Nino, Costituenti e Costituzioni italiane del 1848-49, Vol. secondo, Napoli, Libreria Scientifica Editrice, 1951, pp.173-174.

81. Le Assemblee del Risorgimento, Sicilia, Vol. I, op. cit., pp. 1002-1003. personale d'iniziativa del re, che avrebbe potuto esercitare il diritto in questione indirettamente, per mezzo dei suoi ministri, i quali avrebbero potuto presentare e discutere i progetti di legge ritenuti dal re opportuni e necessari.

Questa trama costituzionale somiglia in parte al sistema disegnato dalla Costituzione nord-americana e a quello francese del 1848. La Costituzione americana afferma l'inesistenza di un diritto d'iniziativa del Presidente, esercitabile in via di fatto o indirettamente tramite i parlamentari di sua fiducia (che possono presentare progetti di legge ritenuti necessari dal Presidente) o attraverso un'ipotesi contemplata dalla Costituzione (art. II, sezione 3), che consiste nel suggerire in modo ufficiale al Congresso di prendere in considerazione determinati interventi legislativi. Si comprende facilmente che la possibilità di indirizzare la politica legislativa del Presidente, da sola potrebbe non impedire al Congresso di emanare, in modo sistematico, leggi contrarie all'indirizzo politico che il Presidente vorrebbe perseguire. Come contrappeso la Costituzione attribuisce al Presidente di esercitare il veto sospensivo. Ogni progetto di legge una volta approvato dal Congresso deve essere inviato al Presidente che deve apporvi la sua firma in modo che possa entrare in vigore come legge. Il Presidente però può decidere di non apporre la firma, in tal caso rinvia l'atto alla Camera che lo ha approvato per prima allegando i motivi secondo i quali ha egli ritenuto di apporre il suo veto. Per superare il veto del Presidente le due Camere devono riapprovare l'atto normativo a maggioranza dei due terzi dei votanti (art. I, sezione 7; il rinvio deve avvenire entro 10 giorni, in caso contrario la legge s'intende come approvata). Si tratta di un intervento attivo nella sfera del legislativo (esercitato sotto forma negativa).

La Costituzione siciliana, pur prevedendo la possibilità di intervento nel campo legislativo per mezzo dei ministri del re (progetti di legge che sarebbero dovuti passare dalle procedure parlamentari secondo il principio che il potere di fare le leggi appartiene esclusivamente al Parlamento), accoglie il potere di veto sospensivo in capo al Re, che può rinviare l'atto normativo con le sue osservazioni entro trenta giorni dalla presentazione e per una sola sessione, ma per superare il quale le Camere avrebbero potuto deliberare a maggioranza assoluta e non il voto favorevole dei $2 / 3$ dei deputati e dei senatori come previsto, invece, dalla Costituzione nord-americana. Questa impostazione siciliana 
somiglia a quella francese del '48; infatti, anche il Presidente della Repubblica francese non partecipa direttamente all'attività legislativa con la sanzione. Al Presidente spettava la promulgazione (art. 56); anche qui si volle un veto meramente sospensivo esercitabile dal presidente nella stessa sessione. Secondo l'art. 58 il presidente, nel termine posto per la promulgazione (un mese per tutte le leggi e tre giorni per le leggi d'urgenza, art.57), può con messaggio motivato, chiedere una nuova deliberazione: “...L'Assemblea delibera: la sua risoluzione diviene definitiva; essa è trasmessa al Presidente della Repubblica. In questo caso, la promulgazione ha luogo entro il termine fissato per le leggi d'urgenza". L'art. 59 prevede, addirittura, che in caso di mancanza di promulgazione da parte del Presidente della Repubblica, vi provvederà il Presidente dell'Assemblea Nazionale nei termini previsti dagli artt. 57 e 58.

Il dibattito parlamentare sul veto e soprattutto sull'eventuale potere di scioglimento del parlamento da riconoscere al re fu molto acceso, alla fine prevalse l'orientamento di attribuire al sovrano solo il veto sospensivo superabile dalle Camere con voto preso a maggioranza assoluta per la seconda approvazione del progetto di legge in discussione e rinviato una sola volta dal re. Secondo l'orientamento prevalente il veto sospensivo si sarebbe trasformato in veto assoluto, dato che da un lato non è facilmente raggiungibile una maggioranza così ampia, dall'altro la breve durata della Camera dei deputati, soggetta ad un frequente ricambio, non avrebbe potuto consolidare un orientamento politico. Sull'argomento si propone la lettura di uno stralcio dell'intervento del deputato Giuseppe Natoli, barone di Scaliti (seduta della Camera dei Comuni del 24 giugno 1848):

Si è invocata la Costituzione americana; ma in verità, il bisogno di trovare due terze parti di rappresentanti e di senatori, convenuti nella sentenza di rigettare l'opposizione del Presidente, è tal cosa difficile, che la legge rare volte può passare. Il veto sospensivo, che può mettere il Presidente americano, le più volte nel fatto diventa veto assoluto [...] Io credo che come avviene in quella Repubblica, il capo del potere esecutivo, dissentendo alla legge che il Parlamento gli presenta, dovrà immantinenti rinviarla alle Camere, le ragioni del suo rifiuto adducendo; se non che le Camere, persistendo nella legge, senz'altra maggioranza che l'assoluta, la legge deve prender forza definitiva e mandarsi subito ad esecuzione.
In questa bisogna, vi è da un lato la maggioranza assoluta delle due Camere legislative, che richieggono una legge, e la volontà sola d'un uomo, di un re, che la nega. Ragionevolmente parlando, il voto delle Camere ha una presunzione di verità mille e mille volte più forte sopra quello del re. Un caso di eccezione, un'osservazione di fatto, una impossibilità pratica di eseguir la legge, possono sostenere il principio d'un veto momentaneo; ma questo veto dev'esser limitato in quei confini che la ragione comanda. Quando il re può sospender la legge da una all'altra sessione, si ammette, che il giudizio di un uomo la vince sul giudizio di tanti. E quando al re non piace la legge, prima di convocarsi la nuova sessione può fare ogni opera perché il suo veto trionfi; la qual cosa succeder non può quando nella stessa sessione alle camere torna la legge ${ }^{82}$.

Dunque, a differenza della Costituzione americana, ma come previsto dalla Costituzione francese del 1848, si volle un veto sospensivo "momentaneo", esercitabile dal re per una sessione (quindi il re poteva differire la promulgazione della legge nella successiva sessione parlamentare), in modo da evitare che il veto sospensivo, così come si era manifestato nell'esperienza costituzionale nord-americana, si trasformasse in via di fatto in veto assoluto.

Al re spettava la promulgazione, che è l'atto del Capo dello Stato con il quale si esterna la volontà legislativa del Parlamento. Il re in seconda approvazione avrebbe dovuto promulgare l'atto normativo che essenzialmente consisteva (e consiste) nella solenne dichiarazione dell'avvenuta approvazione da parte delle Camere della legge di cui si riporta integralmente il testo, a cui fa seguito la clausola di esecutorietà (è fatto obbligo a chiunque spetti di osservala e di farla osservare come legge dello Stato). Rappresenta comunque una forma di intervento del re nel processo legislativo, la promulgazione, infatti, è l'atto finale del procedimento legislativo. La sanzione, invece, è un atto giuridico con cui il sovrano partecipa all'attività legislativa, trasformando il progetto di legge in legge. In caso di rifiuto di sanzione, il progetto di legge non si perfeziona per la mancanza del concorso della volontà del re. La sanzione, a differenza del veto, è partecipazione piena e diretta al procedimento legislativo, il veto, invece, rientra nel diritto di opporsi ad una decisione assunta da altri soggetti (parlamento).

82. Le Assemblee del Risorgimento, Sicilia, Vol. I, op. cit., p. 1006; 
Nel sistema costituzionale inglese il re è uno dei tre organi legislativi (Camera dei Comuni, Camera dei Lords, Corona) ed in quanto tale interviene nel procedimento legislativo (Royal assent). La legge diviene perfetta con l'atto di sanzione del re. Negli Stati Uniti il veto sospensivo esige l'esposizione delle osservazioni in base alle quali è opposto (la sanzione, invece, è una manifestazione della volontà del re che non richiede motivazione). Negli Stati Uniti, la legge esiste indipendentemente dalla volontà del Presidente che può eventualmente manifestarsi in una seconda fase, cioè nella fase della promulgazione, prima di effettuare la quale può essere opposto il veto.

La Costituzione siciliana del 1848 fa proprio questo istituto tipico della forma repubblicana (ma sceglie la monarchia), perché non implica la diretta partecipazione del Capo dello Stato al procedimento legislativo. Il Parlamento siciliano volge lo sguardo in parte al sistema costituzionale nord-americano e anche al sistema francese del '48 (pur non scegliendo la forma repubblicana), avendo cura però di rafforzare i poteri delle Camere, quindi assicurare ad esse la preminenza costituzionale, e indebolire quelli del re (veto meramente sospensivo, esercitabile per una sessione e superabile, in caso di dissenso con le osservazioni opposte dal re, con la maggioranza assoluta e con quella dei $2 / 3$ )

\section{IL RE CAPO DI STATO E DI GOVERNO. DUE POTERI QUASI UGUALI: LE CAMERE NON POTEVANO REVOCARE IL RE E IL RE NON POTEVA SCIOGLIERE IL PARLAMENTO. RESPONSABILITA' GIURIDICA (E NON POLITICA) DEI MINISTRI DEL RE PER GLI ATTI DA ESSO COMPIUTI}

Lo Statuto siciliano, come negli Stati Uniti e come in Francia con la Costituzione repubblicana, prevede un Esecutivo con a capo il re, Capo di Stato e di Governo. L'Esecutivo è scelto dal re, la stessa Costituzione non accenna a nessun vincolo fiduciario, cioè non prevede la fiducia del parlamento. Negli Stati Uniti l'Esecutivo è rappresentato dal Presidente, Capo di Stato e di Governo, ed è eletto senza la mediazione del Congresso e senza vincolo di fiducia nei confronti del parlamento. Anche in Francia il potere esecutivo è esercitato dal Presidente della Repubblica anch'egli eletto direttamente dal popolo e davanti a quest'ultimo responsabile.
Come la Costituzione siciliana, anche quella francese del ' 48 creava due poteri uguali senza indicare nessun mezzo per risolvere i conflitti che sarebbero potuti sorgere tra loro: l'Assemblea Legislativa non poteva revocare il Presidente della Repubblica e il Presidente non poteva sciogliere l'Assemblea Legislativa. Come nella Costituzione siciliana (art.14, secondo comma), in Francia i ministri potevano essere scelti anche all'interno dell'Assemblea, ma fu difficile aprire la strada al parlamentarismo (l'art. 49 prevede il diritto del presidente della Repubblica di presentare progetti di legge all'Assemblea nazionale tramite i ministri) ed all'eventuale emarginazione del ruolo politico del Presidente della Repubblica (lo dimostra il breve periodo di governo di Odilon Barrot, nominato dal Presidente della Repubblica Luigi Napoleone il 30 dicembre 1848 e dallo stesso revocato il 30 ottobre 1849 per sostituirlo con il generale d'Hautpoul. Barrot aveva cercato di deliberare, riunito in Consiglio di Gabinetto, senza la presenza del Presidente della Repubblica).

In Sicilia il Parlamento non avrebbe potuto provocare le dimissioni del re (in quanto capo di governo) revocandogli la fiducia, e al re non sarebbe stato riconosciuto il potere di scioglimento del parlamento. Mentre negli Stati Uniti, e in parte anche nella Francia del '48, i due organi, parlamento e Presidente, si trovavano in posizione pienamente paritaria e traevano la loro legittimità dal popolo, dagli elettori. In Sicilia solo le due Camere, cioè il potere legislativo, erano scelte dagli elettori (solo da una ristretta base elettorale, quindi non da tutto il popolo ma di una piccola parte di esso), il re era scelto dal Parlamento (artt. 36,37,38; il Parlamento elesse come re dei Siciliani Ferdinando Amedeo di Savoia, Duca di Genova, che avrebbe assunto il nome di Alberto Amedeo I Re di Sicilia. Il figlio secondogenito dell'allora Re di Sardegna rifiutò il trono) ${ }^{83}$.

Il disegno costituzionale siciliano, pur rimanendo in parte nell'alveo di quello americano e francese rafforza ulteriormente i poteri del Parlamento rispetto a quelli già deboli del re. L'art. 68 disciplina la responsabilità dei ministri (i ministri sono responsabili. Essi potranno essere processati e puniti nei casi e modi stabiliti da apposita legge. Potrà il Parlamento domandar conto dei loro atti, sottoporli a giudizio e punirli. Il

83. Il decreto che elesse il Duca di Genova Re dei Siciliani, emanato subito dopo l'approvazione dello Statuto costituzionale in, Le Assemblee del Risorgimento, Sicilia, Vol. I, op. cit., p. 1153; 
re non potrà far grazia attenuando, commutando o condonando la pena). Si introduce per questa via il potere di impeachment nei confronti non del re ma dei suoi ministri. Quindi nuovamente, nel voler rafforzare i poteri del Parlamento, si discosta dalle regole americane e francesi, dove invece il potere di impeachment era esercitato nei confronti del Presidente (art. I, sez. 3, $6^{\circ}$ e $7^{\circ}$ comma per la Costituzione americana, art. 68 per la Costituzione francese) per approdare solo in parte alla disciplina proveniente dall'esperienza costituzionale inglese immediatamente antecedente alla fase parlamentare. E' necessario chiarire che il sistema americano proviene da una imitazione delle Istituzioni inglesi del periodo della monarchia costituzionale, fase dualistica dell'evoluzione costituzionale inglese che era stata già da tempo superata in Inghilterra ${ }^{84}$. Inoltre, dobbiamo tener presente che nella metà dell'Ottocento, negli Stati Uniti il potere di impeachment del Parlamento aveva perso ogni pratica rilevanza.

Il re siciliano non avrebbe potuto, anche attraverso i suoi ministri, esercitare un'influenza ex post sul parlamento con la sanzione sulla legge del parlamento, mentre il parlamento avrebbe potuto esercitare l'atto di accusa contro i ministri del re (artt. 68 e 69). L'aspetto peculiare è che si tratta di una responsabilità giuridica, fondata sull'accusa e sul giudizio penale contro il ministro, mentre in quegli anni (metà Ottocento) in Inghilterra si era già affermata la responsabilità politica, all'accusa si era sostituita la sfiducia contro i ministri del Governo (che produceva e produce ancora la loro sostituzione con altri ministri). Il re siciliano è sostanzialmente privato di tutti quei poteri che potrebbero consentirgli di intervenire autonomamente, ma nemmeno indirettamente con i suoi ministri, nella determinazione dell'indirizzo politico. Il re non può nemmeno sciogliere il parlamento come statuito dall'art. $33,2^{\circ}$ comma della Costituzione, strumento tipico della monarchia costituzionale il cui significato identifica

84. La formula adottata nel sistema nord-americano è essenzialmente rivolta ad imitare lo stadio dell'esperienza inglese immediatamente antecedente alla fase parlamentare; $c i$ si riferisce cioè allo stadio in cui, in seguito alla lotta tra i tentativi assolutistici della monarchia e la resistenza dei rappresentanti delle varie classi volta a conservare $i$ diritti tradizionali, $s$ stabilisce una specie di compromesso in cui le assemblee rappresentative ottengono l'esercizio del potere legislativo ed il re rimane il potere di governo. La netta separazione dei due poteri attivi (quello legislativo e quello esecutivo) che ne risulta, viene riprodotta nell'ordinamento americano per quel che riguarda i rapporti tra Presidente e Congresso, MORTATI, Costantino, Le Forme di Governo, Padova, Cedam, 1973, p. 84 un aspetto essenziale della forma di governo. Nel Parlamento siciliano il dibattito fu molto acceso fra chi voleva attribuire il potere di scioglimento al re e chi, invece, si oppose fermamente con motivazioni giuridicamente importanti ${ }^{85}$.

Vediamo alcuni passaggi maggiormente significativi. Seduta della Camera dei Comuni del 14 giugno 1848, interviene il deputato Angelo Marocco:

...il progetto che discutiamo dà al Re un rimedio contro la cattiva tendenza del Parlamento, e questo è la facoltà di non pubblicare le leggi da lui decretate, e di attendere che siano discusse in altra sessione. Il Re dunque, che per mezzo di questa esperienza non ha nulla a temere da una Camera, quand'anche si supponesse anarchica, violenta e traditrice degl'interessi del popolo, il Re dico, non ha nessun titolo, nessun pretesto per pretendere al dritto di sciogliere il corpo legislativo. Come dunque potrebbe giustificarsi agli occhi della ragione e della scienza questa facoltà che si propone di accordare al Re? Questo stava bene nelle vecchie Costituzioni, che pensavano di conciliare i due principi opposti della sovranità del Principe e di quella del popolo; ma oggi che è riconosciuto, e che si parte dall'idea di base che la sola sovranità vera ed esistente è quella del popolo; oggi sotto una Costituzione che sembra tratta da quel principio, non può affatto ammettersi senza inconseguenza che il Re possa sciogliere il Parlamento ${ }^{86}$.

Il deputato Francesco Ferrara risponde:

...il dritto di sciogliere la Camera, in vece di essere contrari agli interessi del popolo, è anzi nell'interesse del popolo; perché esso si esercita nel caso in cui la rappresentanza nazionale sia dal potere esecutivo riguardata come sviata dai suoi doveri. In questo caso, se il dritto di sciogliere fosse assoluto, sarebbe pernicioso, ma com'esso è collegato all'obbligo di riconvocare immediatamente, e con lo stesso atto, si riduce a un appello che il potere esecutivo fa all'opinione pubblica, la quale si pronunzia o contro il potere rieleggendo gli stessi rappresentanti, o in suo favore eleggendone nuovi" ${ }^{\prime 7}$.

85. Si veda SPELLANZON, Cesare, Le discussioni del general parlamento di Palermo per la formazione di uno Statuto costituzionale del Regno di Sicilia, in Il Centenario del Parlamento (8 maggio 1848-8 maggio 1948), Roma, Camera dei Deputati, 1948, pp. 29-33.

86. Le Assemblee del Risorgimento, Sicilia, Vol. I, op. cit., p. 884 87. Le Assemblee del Risorgimento, Sicilia, Vol. I, op. cit., pp. 884-885. 
Il deputato Giuseppe Natoli interviene a sostegno di Francesco Ferrara:

L'America ripara al difetto di non potersi sciogliere le Camere riducendo a due anni la deputazione dei suoi rappresentanti; questo esempio invocato dal signor Ferrara, io lo adotto, e ricordo il Senato di quella potente repubblica, il quale deve immancabilmente rinnovellarsi di un terzo ogni biennio [...] Nella Monarchia costituzionale, quando insorge una lotta fra il Re e le Camere bisogna scegliere fra queste o quello; o licenziare il Re, o dissolvete le Camere; due corpi che si urtano non possono più provvedere alla bisogna pubblica. Non credo che si vorrà cangiare di dinastia al primo contrasto fra il Re e le Camere; dunque non resta che l'altro partito ${ }^{88}$.

Decisivi gli interventi dell'avv. Gabriello Carnazza, del barone Vito D’Ondes Reggio e dell' avvocato Giovanni Interdonato:

...il Re ha un interesse proprio e personale di accrescere la propria potenza a spese della libertà [...] ma se voi date il vantaggio al re di sciorre le camere, egli avrà sempre forza e mezzi moltiplici onde mettere in opera le arti subdole, le mene clandestine, i raggiri della sua potenza, onde creare una nuova Camera più sommessa e dipendente ${ }^{89}$;

E riflettete, o signori, che come io reputo che deve essere, e credo che la Camera ugualmente lo reputi, il re non deve avere che il veto sospensivo, e non l'assoluto ${ }^{90}$;

Se si trattasse di un Presidente alla maniera degli Stati Uniti di America, se si trattasse di un re elettivo, i timori dell'abuso di questo potere a lui conferito sarebber minori; [...] Non è così trattandosi di un re e di un re ereditario; è un fatto che la storia ci mostra, è un vizio che tutte le Costituzioni del mondo rivelano, che ogni re costituzionale si affeziona al potere e cerca di ingrandirlo e di svincolarlo ${ }^{91}$.

Lo Statuto afferma che il Parlamento può approvare qualsiasi legge. Esso detiene il potere normativo e nonostante il frequente rinnovo della Camera dei deputati, controlla l'esercizio

88. Ibidem, p. 887.

89. Ibid., p. 890.

90. Ibid., p.892.

91. Ibid., p. 896 . della funzione di indirizzo politico. Aspetti controbilanciati dall'affermazione (artt. 68-69) del principio dell'irresponsabilità regia, che implica la piena responsabilità dei ministri del re per gli atti da questo compiuto; tutti gli atti del re devono essere controfirmati, l'art. 52 introduce l'istituto della controfirma ministeriale negli atti del re (istituto introdotto in Inghilterra con l'Act of Settlement del 1701).

Per il Parlamento si prevedeva l'esercizio dell'atto di accusa (impeachment) contro i ministri del re, tipico controllo repressivo (all'epoca però in Inghilterra si era trasformato lentamente in controllo preventivo che poi sfocerà nell'affermazione della necessità del rapporto di fiducia tra parlamento e governo, da responsabilità giuridica a responsabilità giuridica). Lo Statuto accoglie, nonostante fosse stato concepito nel 1848, il principio della responsabilità giuridica, cioè del controllo repressivo. Le stesse norme prevedevano disposizioni che imponevano al re di esonerare dalla responsabilità i propri ministri e quindi ostacolare la procedura parlamentare di impeachment.

Al principio dell'irresponsabilità regia si contrappose il principio degli "interna corporis"92, anche se non espressamente indicato nello Statuto, ma desumibile dagli articoli 17, 25 e soprattutto dai principi generali, dall'insindacabilità degli atti compiuti dalle Camere al loro interno.

92. Il testo della Costituzione siciliana garantisce l'autonomia e l'indipendenza costituzionale delle Camere, mettendole al riparo dai condizionamenti che sarebbero potuti provenire da altri poteri dello Stato. Ogni Camera era dotata di autonomia normativa, per tutto ciò che avrebbe riguardato la disciplina delle proprie attività parlamentari e della propria organizzazione (anche con riferimento all'autonomia contabile), non è, invece, indicata espressamente l'autodichia, cioè la giurisdizione esclusiva per eventuali ricorsi relativi ai rapporti di lavoro con $i$ dipendenti. Dai principi generali, desumibili dal testo e dagli atti parlamentari, si può ricavare il principio degli interna corporis acta, quindi della sottrazione a qualsiasi controllo esterno degli atti e dei procedimenti che si sarebbero svolti all'interno delle Camere. Il principio dell'insindacabilità degli interna corporis è più in generale, legato alla lotta che i Parlamenti condussero per affermare il loro potere nei confronti del potere regio; la verifica dei poteri, le prerogative parlamentari e l'insindacabilità degli atti interni costituirono $i$ tre pilastri che garantirono l'indipendenza del Parlamento rispetto al potere esercitato dal re; si vedano, SAVIGNANO, Aristide, Gli atti amministrativi delle Camere parlamentari e la loro sindacabilità, in Rassegna di diritto pubblico, 1960, pp. 626-663; ROMANO, Santi, Gli atti di un ramo del Parlamento e la loro pretesa impugnabilità dinanz la IV Sezione del Consiglio di Stato, in Il Circolo Giuridico, Rivista di legislazione e giurisprudenza, anno XXX, Vol. XXX, pp. 77-86, ZANOBINI, Guido, Corso di diritto amministrativo, Vol. II, Milano, 1954, p.131; OCCHIOCUPO, Nicola, Autodichia, in Enciclopedia Giuridica Treccani, Vol. IV, Roma, 1988, p. 3. 


\section{FORMA DI GOVERNO “QUASI DUALISTICA” (DUALISMO ZOPPO 0 INEGUALE)}

Il sistema delineato sembra riconducibile a quello americano e francese, tuttavia il re siciliano può esercitare un veto sospensivo "debole", facilmente superabile con il voto favorevole delle due Camere preso a maggioranza assoluta, mentre il veto sospensivo previsto dalla Costituzione americana può essere rigettato o superato con il voto favorevole dei $2 / 3$ dei Rappresentanti e dei Senatori (spesso non era facile raggiungere una tale maggioranza qualificata, di conseguenza il veto sospensivo in via di fatto si trasformava di volta in volta in "veto assoluto"). Nella Costituzione di Cadice del 1812, invece, non si può parlare di semplice "rinvio" o di veto sospensivo, in quanto il re negata la sanzione su una legge, esercitabile per due anni consecutivi, poteva anche contare non solo sulla breve durata delle sessioni, ma anche sulle rielezioni biennali del parlamento. Anche la possibilità di intervento dei ministri, che possono presentare progetti di legge e discuterli, somiglia abbastanza al sistema americano.

L'altro potere, che caratterizza anche il sistema costituzionale americano ma soprattutto quello inglese, è l'esercizio dell'atto di accusa contro i ministri del re (che si sarebbe dovuto contrapporre però alla "sanzione" sulle leggi del parlamento), esercizio ben disciplinato dalla Costituzione siciliana la cui procedura di accusa era affidata alla Camera dei deputati, mentre il giudizio era affidato alla Camera dei senatori in funzione di Alta Corte del Parlamento (articoli 73 e 74 della Costituzione siciliana). Questa disciplina è mutuata dall'esperienza costituzionale inglese antecedente alle due rivoluzioni. Anche in Inghilterra la competenza giurisdizionale era affidata alla Camera Alta (Camera dei Lords) in funzione di Alta Corte del Parlamento.

Anche la Costituzione francese conteneva norme tendenti ad indebolire $\mathrm{i}$ poteri del Presidente rispetto all'Assemblea. Il Presidente non era immediatamente rieleggibile al termine dei quattro anni di mandato (ma dopo un intervallo di quattro anni, art. 45), poteva disporre della forza armata, senza poterla comandare personalmente (art. 50), non aveva il potere di scioglimento dell'assemblea nazionale, né poteva sospendere o prorogare l'assemblea nazionale. Il numero dei ministri e le loro attribuzioni erano fissati dal Parlamento. Come per la Costituzione siciliana anche la Costituzione francese all'art. 34 stabiliva che i membri dell'Assemblea nazionale erano rappresentanti della Francia intera e non del Dipartimento che li aveva nominati. In conclusione, la Costituzione francese ha esteso i poteri dell'assemblea ed ha limitato quelli del Presidente. Ma una norma sopravanzava su tutte le altre: l'elezione popolare del Presidente della Repubblica annullava la sua inferiorità giuridico-costituzionale e ristabiliva l'equilibrio a suo vantaggio. Un sistema così congegnato rischiava di portare al colpo di Stato (che arrivò il 2 dicembre 1851).

La Costituzione siciliana racchiude una concezione dualistica molto particolare, due corpi costituzionali posti quasi in posizione paritaria: il parlamento e il re. La Costituzione non attribuisce la sovranità al re, ma nello stesso tempo, nonostante i numerosi richiami nel dibattito parlamentare, non viene attribuita al popolo (al limite ai rappresentanti di una frazione di esso). Si può, invece, individuare una supremazia del parlamento e per questa via possiamo affermare, anche se non in modo pieno, la sovranità della Costituzione. Non pienamente perché fra i due organi costituzionali prevale il parlamento sull'altro (re), quindi i rapporti di forza (sul piano politico) tra i due corpi sembrano favorire il parlamento. La Carta siciliana da un lato non presenta una forma di separazione dei poteri assolutamente rigida (prevede la possibilità di reciproca influenza anche se prevalgono i poteri del parlamento), dall'altro non si può parlare di avvicinamento tra i poteri, pur in presenza di una supremazia del parlamento, ma, volendo in parte inseguire l'esempio americano, non introduce una forma "parlamentare".

Per questo motivo non credo che si possa parlare di forma monistica dove, i due poteri, pur derivando da un'unica fonte (la volontà della Nazione), solo ad uno di essi (parlamento) si riconosce la supremazia sull'altro. Questo schema condurrebbe naturalmente al sistema parlamentare, nel quale al solo parlamento spetta di decidere l'indirizzo politico e nel quale il Governo è vincolato dal rapporto di fiducia che lo lega al parlamento. Nella Costituzione siciliana però manca la caratteristica essenziale di un sistema di equilibrio tra i poteri, fra loro distinti ma posti su un piano di parità: il debole intervento, attraverso i ministri del re nel processo legislativo, non può neutralizzare la supremazia della funzione legislativa, essendo questa esercitata (nel sistema parlamentare 
appunto) dal parlamento e dal re con la sanzione (quando il parlamento eserciterà non solo il potere legislativo, ma determinerà l'indirizzo politico attraverso i ministri, quest'ultimi saranno legati ad esso da un rapporto di fiducia: da ministri del re a ministri legati al parlamento da un rapporto di fiducia).

Dunque, unica fonte di derivazione (ma non di estrazione), i due poteri, legislativo ed esecutivo, si costituiscono in due centri di autorità distinti, congegnati in un modo tale ed unico da potersi definire di forma "quasi dualistica" o di "dualismo zoppo", proprio perché i due attori costituzionali non sono in linea di principio in posizione assolutamente "paritaria". La forma dualistica pura comporterebbe una rigida separazione dei poteri, che nella meccanica costituzionale siciliana è formalmente dichiarata, ma poi sostanzialmente afferma la supremazia del parlamento sugli altri organi (che sarebbe invece tipico dei sistemi monistici puri).

\section{CONCLUSIONI}

Dalla Costituzione siciliana emerge una forma istituzionale "eclettica" o "mescidata", tra l'impianto costituzionale americano, francese del '48 e quello inglese precedente alle due grandi rivoluzioni. Lo schema siciliano implicherebbe una separazione dei poteri che renderebbe possibile l'influenza ex post di un organo sulla funzione dell'altro, uno dei due organi costituzionali è però claudicante: il re, pur partecipando (indirettamente) per mezzo dei ministri alla funzione legislativa, non è uno dei tre organi legislativi, non interviene personalmente nel processo legislativo, la Costituzione priva il re di intervenire con l'atto di sanzione, ma attribuisce ad esso lo strumento del veto sospensivo "limitato". Tale istituto non implica la diretta partecipazione del re al processo legislativo. Il re può solo intervenire in una seconda fase, della promulgazione prima di effettuare la quale può opporre il veto. Quindi, si manifesta in un momento successivo rispetto alla formazione della legge, ponendosi come strumento di formale condizionamento da parte del re rispetto al Parlamento. Inoltre, il veto, a differenza della sanzione (manifestazione della volontà del re che non necessita di motivazione) comporta l'esposizione delle osservazioni, cioè è necessario motivare l'opposizione.
Fra i due organi costituzionali prevale il parlamento sul re. Il disegno costituzionale siciliano rafforza volutamente i poteri del parlamento rispetto a quelli già deboli del re. Non si tratta di un vero e proprio abbandono del modello del "King in Parliament", ma di una soluzione "eclettica" tutta tesa a limitare il potere del re (da leggere in senso anti-borbonico ${ }^{93}$ ). Tutte le norme relative al potere esecutivo sono orientate a ridurre il potere regio.
93. Camera dei Comuni, sessione del 9 giugno 1848, in Assemblee del Risorgimento, Atti raccolti e pubblicati per deliberazione della Camera dei Deputati, Sicilia, cit., pp. 827-836; per gli aspetti generali si veda, CONDORELLI, Mario, Stato e Chiesa nella rivoluzione siciliana del 1848, Catania, Bonanno, 1965, p. 32. 


\section{BIGLIOGRAFIA}

\section{FonTI}

- Art. 14 della Carta francese del 4 giugno 1814 in Saitta, Armando, Costituenti $e$ costituzioni della Francia moderna, Torino, Einaudi, 1952.

- Art. 26 della Dichiarazione dei diritti dell'uomo e del cittadino, Atto Costituzionale del 24 giugno 1793, in Saitta, Armando, Costituenti e costituzioni della Francia moderna, Torino, Einaudi, 1952.

- Atto sovrano n. 79 del 6 marzo 1848, in Collezione delle Leggi e de' decreti reali del Regno delle Due Sicilie, anno 1848, n. 5.

- Bullettino di notizie sul conto delle trattative col re di Napoli, in Collezione Officiale degli Atti del Comitato Generale di Sicilia nell'anno 1848, n. 91.

- Carta costituzionale francese del 1830, in Saitta, Armando, Costituenti e Costituzioni della Francia moderna, Torino, Einaudi, 1952.

- Codice per lo Regno delle Due Sicilie, Leggi Civili, Napoli, Stabilimento tipografico di Domenico Capasso, 1848.

- Collezione di Atti e Sessioni del general Parlamento di Sicilia colle leggi e decreti sancite dalle Camere Legislative, anno $1^{\circ}$ della Rigenerazione, Palermo, Dalla Stamperia Carini, 1848

- Collezione Officiale degli Atti del Comitato Generale di Sicilia nell'anno 1848, Palermo, nella Stamperia e Libreria di Antonio Muratori, Tipografo del Ministero della Giustizia, 1848.

- Costituzione de Bayona de 1808, disponibile su www.juntadeandalucia.es.

- Costituzione del Regno del Belgio (7 febbraio 1831), in Costituzioni straniere contemporanee, Vol. I (a cura di ) Paolo Biscaretti di Ruffia, Milano, Giuffrè, 1989

- Costituzione del Regno delle Due Sicilie del 10 febbraio 1848 in Le Costituzioni italiane (a cura di), Aquarone, Alberto, D’Addio, Mario, Negri, Guglielmo, Milano, Edizioni di Comunità,1958.
- Costituzione degli Stati Uniti d'America, disponibile su www.senate.gov

- Costituzione di Cadice del 1812, disponibile su www.dircost.di.unito.it.

- Costituzione siciliana del 1812, in Le Costituzioni italiane (a cura di), Aquarone, Alberto, D’Addio, Mario, Negri, Guglielmo, Milano, Edizioni di Comunità,1958.

- Decreto de' 24 marzo 1817 relativo alle attribuzioni del supremo consiglio di cancelleria ed alla sua organizzazione, in Le Leggi Amministrative del Regno delle Due Sicilie pe' dominj al di qua e al di la del Faro (per cura di Francesco Dias), Napoli, Tipografia de' Classici Italiani, 1845.

- Decreto n. 221 del 17 maggio 1848, in Collezione delle leggi e de' decreti Reali del Regno delle Due Sicilie, anno 1848.

- Decreto che elegge il Duca di Genova Re dei Siciliani, in Le Assemblee del Risorgimento, Sicilia, Vol. I, Roma, Tipografia della Camera dei Deputati, 1911.

- Decreto portante delle riforme alla legge elettorale provvisoria, $n$. 143, del 5 aprile 1848, in Collezione delle leggi e de' decreti Reali del Regno delle Due Sicilie, anno 1848, n.3.

- Deliberazione della Municipalità di Palermo, e del Comitato provvisorio, che costituisce quattro Comitati per occorrere ai pubblici bisogni, Palermo, 14 gennaio 1848, in Collezione Officiale degli Atti del Comitato Generale di Sicilia nell'anno 1848, Palermo, nella Stamperia e Libreria di Antonio Muratori Tipografo del Ministero della Giustizia, 1848.

- Le Assemblee del Risorgimento, Atti raccolti e pubblicati per deliberazione della Camera dei Deputati, Sicilia, Vol. I, Roma, Tipografia della Camera dei Deputati, 1911.

- Legge elettorale provvisoria per la convocazione della camera de' deputati de' 29 febbrajo 1848, n. 61 (pubblicata il 1 marzo 1848), in Collezione delle leggi e de' decreti reali del Regno delle Due Sicilie, 
Anno 1848, Semestre I, n. 3, Napoli, dalla Stamperia Reale, 1848.

- Legge fondamentale del regno delle Due Sicilie dell'8 dicembre 1816, in Collezione delle leggi de' Decreti Reali del Regno delle Due Sicilie, numero 565, Napoli, Stamperia Reale, 1816.

- Legislazione Positiva del Regno delle Due Sicilie, dal 1806 fino a tutto il 1848 (a cura di Francesco Dias), Napoli, presso Borel e Bompard, 1846.

- Parliamentary History, Statutes of the Realm, volumi 5 e 6, John Raithby Editor, 1819, British History.

- Proclama affisso per le vie di Palermo nei giorni che precedettero la grande Insurrezione, in Ruggero Settimo e la Sicilia, Documenti sulla Insurrezione Siciliana del 1848, Palermo, marzo 1848.

- Rapporto della Commissione incaricata di presentare un lavoro preparatorio sull'atto di convocazione del General Parlamento di Sicilia, in Collezione Officiale degli Atti del Comitato Generale di Sicilia nell'anno 1848, Palermo, Nella Stamperia e Libreria di Antonio Muratori tipografo del Ministero della Giustizia, 1848.

- Risposta del Comitato Generale del 13 febbraio 1848, in Collezione Officiale degli Atti del Comitato Generale di Sicilia nell'anno 1848, Bullettino n. 55, Palermo, nella Stamperia e Libreria di Antonio Muratori, Tipografo del Ministro della Giustizia, 1848.

- Statuto fondamentale del Regno di Sicilia (10 luglio 1848), in Le Costituzioni italiane (a cura di), Aquarone, Alberto, D'Addio, Mario, Negri, Guglielmo, Milano, Edizioni di Comunità,1958.

- Suffragio universale e analfabetismo, Appunti statistici, Vol. CLIII, Serie V - 16 maggio 1911, in BPR - Bibliografia del Parlamento italiano e degli studi elettorali, a cura della Biblioteca della Camera dei deputati, disponibile su www.bpr.camera.it.

- The Act of Settlement of 1701, disponibile su www.royal.uk/act-settlement-0.
- The Federalist no. 57, New York Packet, Tuesday february 19, 1788, James Madison, disponibile su https://constitution.org.

\section{Letteratura}

- Alcalá, Humberto Nogueira, Regimenes politicos contemporaneos, Santiago, Editorial Jurídica de Chile, 1993.

- Condorelli, Mario, Stato e Chiesa nella rivoluzione siciliana del 1848, Catania, Bonanno, 1965.

- Cortese, Nino, Costituenti e Costituzioni italiane del 1848-49, Vol. secondo, Napoli, Libreria Scientifica Editrice, 1951.

- Cortese, Nino, Introduzione alle Costituzioni Italiane del 1848-49, Napoli, Libreria Scientifica Editrice, 1959.

- crisafulli, Vezio, Profili costituzionali di una rivoluzione mancata, in Il 1848, Raccolta di saggi e testimonianze, Roma, Quaderni di "Rinascita", a cura di G. Manacorda, n. 1 del 1948, pp.49-56.

- de bonald, Louis, Réflexions sur la révolution de juillet 1830 et textes inédits, Présentation et analyse de Jean Bastier, Paris, co-édition Duc-Albatros, 1988.

- dicey, Albert Venn, Introduction to the study of the Law of the Constitution, London, Macmillan and co. and New York, 1889.

- Di Gregorio, Pinella, Nobiltà e nobilitazioni in Sicilia nel lungo Ottocento, in Meridiana, Rivista di Storia e Scienze Sociali, n. 19, 1994, Roma, Casa Editrice Donzelli, pp. 83-112.

- Di Matteo, Salvo, Storia dell'antico parlamento di Sicilia (1130-1849), Palermo, Graficreo, 2012.

- Falzone, Gaetano, Il problema della Sicilia nel 1848 attraverso nuove fonti inedite, Indipendenza e autonomia nel giuoco della politica internazionale, Palermo, A. Priulla Editore, 1951.

- Gemelli, Carlo, Storia della siciliana rivoluzione del 1848-49, Bologna, Giuseppe Legnani Editore, 1867.

- Genovesi, Giovanni, Storia della Scuola in Italia dal Settecento a oggi, Bari, Laterza, 2004. 
- Gilissen, John, Die belgische verfassung von 1831 - ihr ursprung und ihr einfluss, in W. Conze (Hrsg), Beiträge zur deutschen un belgischen verfassungsgeschichte im 19 , Jahrhundert, Stuttgart, 1967, pp. 38-69.

- Grimaldi, Angelo, La Costituzione siciliana del 1812, in Revista de Derecho, Vol. 48, julio-diciembre 2017, Barranquilla, División de Derecho, Ciencia Politica y Relaciones Internacionales de la Universidad del Norte, Colombia, pp. 208-233.

- Grimaldi, Angelo, La Insurrección Siciliana de 1820. Aspectos Politico-Constitucionales, Revista de Estudios Histórico-Jurídicos, n. 40, Escuela de Derecho, Pontificia Universidad Católica de Valparaíso, Chile, 2018, pp. 213-235.

- Hallam, Enrico,Storia costituzionale di Inghilterra, dal cominciamento del Regno di Enrico VII alla morte di Giorgio II, prima traduzione italiana dall'originale inglese del Barone Vito D'Ondes Reggio, Vol. IV, Torino, UTET, 1855.

- La Masa, Giuseppe, Documenti della rivoluzione siciliana del 1848-49 in rapporto all'Italia, illustrati da Giuseppe La Masa, vol. primo, Torino, Tipografia Ferrero e Franco, 1850.

- Mortati, Costantino, Le Forme di Governo, Padova, Cedam, 1973.

- Novarese, Daniela, Assemblee parlamentari $e$ potere costituente in Sicilia (18121848) in, De curia semel in anno facienda. L'esperienza parlamentare siciliana nel contesto europeo (a cura di A. Romano), Atti del convegno internazionale di studi (Palermo, 4-6 febbraio 1999), Milano, Giuffrè, 2002, pp.144-146.

- Occhiocupo, Nicola, Autodichia, in Enciclopedia Giuridica Treccani, Vol. IV, Roma, 1988.

- Pelleriti, Enza, 1812-1848. La Sicilia fra due Costituzioni, Milano, Giuffrè, 2000.

- Racioppi, Francesco, Brunelli, Ignazio, Commento allo Statuto del Regno (con prefazione di Luigi Luzzatti), Vol. I, Torino, UTET, 1909.
Riall, Lucy, La Sicilia e l'unificazione italiana. Politica liberale e potere locale (1815-1866), Torino, Einaudi, 2004.

- Romano, Salvatore Francesco, Il'48 in Sicilia, in Il 1848, Raccolta di saggi e testimonianze, Roma, Quaderni di "Rinascita", a cura di G. Manacorda, n. 1 del 1948, pp.101-108.

- Romano, santi, Gli atti di un ramo del Parlamento e la loro pretesa impugnabilità dinanzi la IV Sezione del Consiglio di Stato, in Il Circolo Giuridico, Rivista di legislazione e giurisprudenza, anno XXX, Vol. XXX.

- San Martino De Spucches, Francesco, La storia dei feudi e dei titoli nobiliari di Sicilia, Palermo, Scuola Tipografica "Boccone del Povero", 1927.

- Savignano, aristide, Gli atti amministrativi delle Camere parlamentari e la loro sindacabilità, in Rassegna di diritto pubblico, 1960, n.3-4.

- Sciumbata, Letizia, Rita, Un modello di Stato federale: il Belgio, in Istituto di Studi sui Sistemi Regionali Federali e sulle Autonomie "Massimo Severo Giannini" (ISSIRFA), disponibile su www.issirfa.cnr.it

- Simoncini Scaglione, Giovanni, Dal 48 al 60, Ricordi storici, Palermo, Carmelo Maniscalco Editore, 1890.

- Spellazon, Cesare, Le discussioni del general parlamento di Palermo per la formazione di uno Statuto costituzionale del Regno di Sicilia, in Il Centenario del Parlamento (8 maggio 1848-8 maggio 1948), Roma, Camera dei Deputati, 1948.

- Spellanzon, Cesare, Storia del Risorgimento e dell'Unità d'Italia, Vol. III, Milano, Rizzoli \& C., 1936.

- Turotti, Felice, Storia d'Italia continuata da quella di Carlo Botta, dal 1814 al 1854, Volume terzo, Milano, Pagnoni, Tipografo Editore, 1855.

- Villari, Rosario, Storia dell'Europa contemporanea, Vol. I, Laterza, 1975.

- Zanobini, Guido, Corso di diritto amministrativo, Vol. II, Milano, Giuffrè, 1954. 